\title{
RECURSOS COMPARADOS RELATIVOS A LADETERMINACIÓN DEL VÍNCULO CAUSAL. UN ANÁLISIS CENTRADO EN EVENTOS DE RESPONSABILIDAD SANITARIA
}

\section{COMPARED RESOURSES RELATIVE TO THE DETERMINATION OF A CAUSAL LINK. AN ANALYSIS FOCUSED ON EVENTS RELATED TO HEALTH RESPONSABILY}

Renzo Munita M."

\begin{abstract}
"Si, sin embargo, una decisión, se pronuncia en este país, ofendiendo el sentido básico de justicia, y si la consideración de fuentes internacionales sugiere que una decisión diferente y más aceptable se pronunciaría en la mayoría de las jurisdicciones, cualquiera sea su tradición jurídica, deberá verificarse prontamente una revisión de la decisión en cuestión"
\end{abstract}

\section{RESUMEN}

La incertidumbre científica ligada al desarrollo tecnológico repercute sobre las víctimas en pleno siglo XXI, en particular respecto de la acreditación del nexo causal siempre necesario para justificar una acción de responsabilidad civil. Sensibles contenciosos, muchos de ellos vinculados a la salud pública, representan en gran medida el problema que nos proponemos estudiar. El Derecho Comparado ha leído la dificultad expuesta arribando a soluciones de las que se desprende un interés por flexibilizar las reglas de prueba, en favor de la determinación de la pretendida causalidad. Hemos constatado en nuestro estudio el recurso jurisprudencial o legal

* Magíster y doctorando en Derecho Privado por la Universidad Pierre Mendès France, Grenoble 2, Francia. Profesor becario Derecho Civil, Universidad del Desarrollo. Becario programa Becas Chile-CONICYT. Dirección postal: Ainavillo 45, Concepción. Artículo recibido el 15 de septiembre de 2014 y aceptado para su publicación el 14 de octubre de 2014.

1 "If, however, a decisionisgiven in this country whichoffendsone's basic sense of justice, and if consideration of international sources suggeststhat a different and more acceptable decisionwouldbegiven in mostotherjurisdictions, whatevertheirlegal tradition, this must prompt anxiousreview of the decision in question”. Fairchild v. Glenhaven Funeral Servs. Ltd, (2002), cons. 32. 
a la responsabilidad solidaria y, en menor medida, a la responsabilidad proporcional, así como a las presunciones a título de mecanismo de inferencia causal. Dichas herramientas representan respuestas de la adaptación jurídica que diversos ordenamientos han observado con el propósito de ofrecer garantías resarcitorias al dañado, que involucrado en un escenario de fatalidad científica se ha visto afectado por partida doble, sea respecto de su daño evidente, sea respecto de la incertidumbre causal que pone en riesgo su resarcimiento.

Palabras clave: incertidumbre causal, responsabilidad solidaria, responsabilidad proporcional, presunciones.

\section{AbSTRACT}

The scientific certainty linked to technological development impacts on victims in this xxi century, particularly, in the accreditation of the causal link, which is always necessary to justify a tort action. Sensitive trials, many of them related to public health, largely shows the problem we intend to study. Comparative law has exposed this difficulty, arriving at solutions that show an interest into make flexible rules of evidence in favor of the proposed causality. We've found in our research the recourse to the solidarity responsibility, and to a lesser extent the proportionate responsibility, as well as the evidential presumptions by way of diverse mechanisms of causal inference. These solutions represent responses of legal adaptation which have been observed in order to provide guarantees to the damaged that, in a scientific doom scenario, has been affected twice: whether about their apparent damage, whether about the causal uncertainty that threatens her compensation.

Keywords: uncertain factual causation, several liability, proportional liability, evidential presumptions.

\section{INTRODUCCIÓN}

El cotidiano consumo de productos, la exposición a diversas partículas o, incluso, el tecnicismo desarrollado por intervenciones médicas, envuelve riesgos y peligros para el hombre. Habiéndonos pronunciado en un anterior trabajo sobre este fenómeno ${ }^{2}$, nos remitiremos aquí a establecer que

${ }^{2}$ Munita (2014), pp. 453-482. 
en función a que los avances científicos y tecnológicos se apoderan del escenario de la innovación, el velo de la inseguridad impacta a la población provocando nuevas interpretaciones de las herramientas disponibles o, derechamente, cambios en los modelos de resarcimiento. Dejamos claro que nuestro objetivo de ninguna manera consiste en apuntar al avance tecnológico como una suerte de producción diabólica de nuestro tiempo. Es más, estimamos que mucho le debe la especie humana a la ciencia y a la tecnología. Innumerables son las mejoras en la calidad de vida de los individuos que están involucrados a determinados focos de explotación tecnológica. Sin embargo, no debemos dejar de reconocer, que una parte trascendente de la naturaleza del desarrollo científico está compuesta por el carácter incierto de las consecuencias dañosas de una investigación sin fronteras, en ocasiones imprudente. De aquí que pueda colegirse, que así como el hombre está a la cabeza de innumerables prodigios, también se encuentra en la base de daños catastróficos. Siguiendo a la profesora Geneviève Shamps, apuntamos:

"Focos de peligro muy diversificados han aparecido durante el curso del siglo $\mathrm{Xx}$, en numerosos dominios: los transportes por tierra, aire, mar, de personas, de bienes, de mercaderías peligrosas o de hidrocarburos, de conducción de gas, agua, electricidad (...), la explotación de energía nuclear, eléctrica o mecánica, el envío de equipos al espacio, la utilización de sustancias químicas, bacteriológicas, explosivas o de otra naturaleza, los productos defectuosos, las transfusiones de sangre, la administración de hormonas, las vacunas, las investigaciones o experimentaciones biomédicas, las manipulaciones genéticas, las biotecnológicas, etc." ${ }^{3}$.

Lo expuesto justifica que los ordenamientos jurídicos de varios países se hayan interrogado sobre su capacidad de adaptación respecto de los avances de la era en la que nos desarrollamos. En este sentido, podemos afirmar que la sociedad contemporánea, si bien se caracteriza por una amplia capacidad de materializar figuras de progreso, es también capaz de proyectar nuevas fuentes de daño que desde perspectivas tradicionales no resisten ser calificadas como causadas por el agente en cuestión. Se desprende de lo anterior la nueva lectura que impacta a la responsabilidad civil. La cual está marcada por una observación científica incapaz de abarcar la integridad de supuestos de un mundo tecnológicamente incierto ${ }^{4}$, y que ubica al instituto en medio de una encrucijada entre el rechazo del

\footnotetext{
${ }^{3}$ Shamps (1998), p. 4.

${ }^{4}$ Boutonnet (2002), p. 1
} 
resarcimiento por defecto causal, o en la voluntad por establecer nuevas asimilaciones del vínculo.

El recurso resarcitorio se enfrenta hoy día a la incertidumbre científica, la cual obliga a la responsabilidad civil a navegar por aguas menos evidentes que las de antaño. En efecto, aquella realidad justificable y clara que sustentaba a la responsabilidad en un perfecto esquema binario de causa y efecto (daño) en variados dominios ya no se aprecia con total nitidez, y la vacilación gana terreno amenazando a las víctimas de hacer frente a un daño injustamente provocado, sin posibilidad alguna de obtener una indemnización al respecto. Como veremos, se constata que algunos ordenamientos a modo de ofrecer una mejor garantía a la víctima contemplan normas de responsabilidad solidaria exponiendo a quienes posiblemente no han causado el daño a ser condenados al resarcimiento de la integridad de este. Otras legislaciones consideran soluciones, menos severas, que atienden al grado de participación del supuesto agente en el daño reteniendo una responsabilidad proporcional cuyos factores esenciales se traducen en el riesgo, su incremento y la conducta del agente. Particular resulta esta especie de responsabilidad, pues el papel que cumple la probabilidad o proporcionalidad no es otro que servir de mecanismo cuantificador del vínculo causal, lo cual criticamos desde ya. A su turno, hacemos presente 212 que, si bien constituyen excepciones aquellos ordenamientos jurídicos que optan por un régimen de responsabilidad proporcional, varios modelos de responsabilidad civil retienen un particular mecanismo probabilístico cual es la figura de la pérdida de la chance o de la oportunidad. Hacemos presente que sobre la institución indicada ya nos pronunciamos en un anterior trabajo ${ }^{5}$, nos remitimos a él, así como a un completo análisis de la figura abarcado por una reciente obra de la doctrina nacional ${ }^{6}$.

El problema de la causalidad supondría un doble análisis, de ahí su dificultad para su determinación 7 . En efecto, respecto del establecimiento del vínculo, tanto la víctima como el supuesto agente, se verán expuestos a su inferencia desde una perspectiva general y a la vez particular. En cuanto a su demostración general podemos decir que no se refiere al daño sufrido por la víctima en su especificidad, sino, más bien, a la acreditación que una substancia, por ejemplo, esté en condiciones de producir el daño cuyo resarcimiento es alegado. En términos simples: que un determinado contaminante tenga el poder suficiente para generar un cáncer al pulmón o una esclerosis múltiple. En este ámbito, la prueba producida será basada principalmente en estadísticas, análisis o estudios epidemiológicos. Luego,

\footnotetext{
${ }^{5}$ Munita (2013), pp. 395-441.

${ }^{6}$ Rios y Silva (2014), pp. 1-304.

${ }^{7}$ KhOury (2007), p. 136.
} 
una vez verificada la prueba de la causalidad abstracta el tribunal deberá detenerse en si dicha substancia ha causado el daño cuyo resarcimiento es solicitado, es decir, en la determinación de la causalidad particular. Así, corresponderá despejar la contingencia relativa a que el contaminante ha provocado el cáncer, o si, por el contrario, la enfermedad ha sido la consecuencia de un historial de adicción al cigarrillo. En este escenario, la prueba deberá ajustarse a un grado de certeza al 100\% (la cual cuestionablemente puede ser identificada con una determinación científica del vínculo) o al requerido por las legislaciones que adoptan el esquema de la balanza de probabilidades en la determinación del nexo.

La distinción antes expresada ha sido formalmente retenida por el Restatement (third) of torts liability for physical and emotional harm, en su sección 28 c, respecto del capítulo de toxic torts. Hacemos presente que la formulación redactada por el American Law Institute, ha sido objeto de observaciones ${ }^{8}$. Ellas se han formulado respecto de una eventual doble causalidad, la cual bien puede inducir al intérprete a la noción de una doble prueba. Consideramos que la retención de la causalidad obedece ante todo a un razonamiento jurídico, el cual bien puede fundarse en análisis científicos, aunque no de manera exclusiva. Así, las nociones meramente intelectuales de causalidad general y específica no deben ser entendidas como elementos de la causa cuya existencia debe demostrarse, debiendo ser suficiente para dar por establecido prima facie el vínculo, la presentación de evidencias razonables respecto de la conexión entre hecho generador y daño. De aquí que sigamos, en este punto, a Joseph Sanders quien sostiene, que "estas categorías funcionan como dispositivos para organizar el análisis de un tribunal, no como elementos formales de la causa de acción" ".

De lo dicho apreciamos la dificultad que puede presentar a la víctima de un daño la prueba de la causalidad, cuando esta es científicamente incierta. En el dominio médico, la condición fisiológica de la víctima, o un periodo de latencia luego del cual se manifestó la enfermedad, pueden, en definitiva, hacer ilusorio el resarcimiento. Respecto de los daños derivados por productos farmacéuticos también se presenta la dificultad probatoria. En este sentido, las dudas relativas a si un producto constituye el origen de un daño, generalmente conducen al desconocimiento de la causalidad desde una perspectiva abstracta. Por otro lado, en el escenario medioambiental, la incertidumbre es constatable respecto de aquellas contaminaciones que se verifican en cercanías de una o varias actividades industriales, en atención

${ }^{8}$ Hudson (2010), pp. 10-13.

9 "These categories function as devices to organize a court's analysis, not as formal elements of the cause of action”, SANDERS (2009), p. 5. 
a la cual resulta difícil determinar si el daño se ha verificado por causas naturales o derivadas de la actividad de la o de las propias empresas ${ }^{10}$.

En fin, diversas afecciones pueden presentarse en torno a la modernidad y en consecuencia ser atribuidos a la acción del progreso: problemas cardiacos, angustias o miedos, incluso cáncer o alergias son especies de los peligros del desarrollo actual. Así, radiaciones electromagnéticas o productos químicos, tales como fertilizantes o pesticidas, han sido considerados, por una parte de los científicos, como los causantes de determinados daños ${ }^{11}$. Desprendemos de lo anterior la motivante tarea que debe asumir el juez de un contencioso en el que la tecnología se encuentra involucrada, pues más allá de dar fe a un determinado informe científico y resolver en consecuencia, corresponderá a su propia instrucción, extra jurídica por cierto, brindar las herramientas suficientes para ser capaz de dirimir cuestiones con autoridad ${ }^{12}$. En esta perspectiva el papel formativo del juez resulta fundamental, pues debe procurar adquirir conocimientos técnicos en diversas áreas, que le permitan valorar el nivel de los trabajos científicos a veces contradictorios, a los cuales acceda en su tarea por decidir un asunto gobernado en ocasiones por la incertidumbre o, incluso, por el impacto mediático de determinados eventos.

El resarcimiento, en nuestro entender, debe diseñarse en escenarios 214 ligados a la innovación, según la integración de mecanismos o técnicas jurídicas cuyo objetivo corresponda a sortear el obstáculo de la incertidumbre científica. De aquí que la búsqueda de una causalidad jurídica no permita ser identificada como un sinónimo ciego de certeza desde la perspectiva tecnológica. Es por lo anterior que inspirándonos en uno de los considerandos de la sentencia Daubert v. Merrell Dow Pharmaceuticals, Inc. ${ }^{13}$, que indica:

"existen importantes diferencias entre la búsqueda de la verdad en el tribunal y la búsqueda de la verdad en el laboratorio. Las conclusiones científicas están sujetas a una revisión permanente. El Derecho, en cambio, debe resolver conflictos definitiva y rápidamente",

cuestionamos la postura tendiente a rechazar la indemnización en caso que, pudiendo ser probada la causalidad mediante criterios jurídicos, no pueda ser demostrada mediante un estricto análisis científico.

${ }^{10}$ En este sentido, Khoury (2009), p. 138.

${ }^{11}$ Vinculando las contingencias expresadas en el párrafo con el principio de precaución, desde la perspectiva del Derecho argentino, BERros (2013), pp. 1-442.

${ }^{12}$ Sobre este punto, véase infra, pp. 248-249.

${ }^{13}$ Daubert v. Merrill Dow Pharmaceuticals, Inc., (1993), p. 597. 
Pues bien, estimamos que el problema referido puede ser estudiado desde un doble escenario. Es así como:

I. la incertidumbre científica y su repercusión en los modelos de resarcimiento: contrastaremos el acceso a una reparación íntegra mediante el recurso a la responsabilidad solidaria, respecto de eventos en los que el daño haya sido cometido por un miembro indeterminado de un grupo; con el recurso a medidas proporcionales, retenidas desde la perspectiva del eventual agresor, como mecanismo de recuperación del equilibrio perdido, determinadas en atención a un cálculo aproximativo de la probabilidad que la conducta del agente haya participado en la gestación del mal;

II. nos pronunciaremos sobre el recurso a las presunciones, que justificadas en la creación del riesgo, constituyen herramientas de alteración de rigideces probatorias en favor de la víctima que carece de atributos jurídicos para ser calificada como tal, pues dentro del proceso causal existen factores desconocidos; en esta parte entonces, nos pronunciaremos sobre el papel de las presunciones en tanto modelo de inferencia del vínculo causal, sección que aprovecharemos para hacer referencia al esquema estadounidense y la prueba de la causalidad en el capítulo de los toxic torts.

\section{LA INCERTIDUMBRE CIENTÍFICA Y SU REPERCUSIÓN}

EN LOS MODELOS DE RESARCIMIENTO: ENTRE LA SOLIDARIDAD

Y LA PROPORCIONALIDAD

La innovación científica genera situaciones en las que es imposible determinar quién es el autor de un daño, no obstante disponerse de la certeza que el perjuicio ha sido causado por uno de los miembros -indeterminado-de un grupo determinado ${ }^{14}$. Nos referimos a episodios de causalidad alternativa, figura que ha motivado el pronunciamiento de ordenamientos jurídicos de países referentes de los sistemas romano-continental como anglosajón. Las soluciones constatadas se estructuran en torno a dos grandes corrientes. Por un lado, aquellos que contemplan sea legal, jurisprudencial o ambos,

\footnotetext{
${ }^{14}$ Respecto de la doctrina nacional, constituye referencia obligada el aporte del profesor Rodrigo Barría D. En efecto, el autor luego de referirse a las soluciones doctrinarias que se han propuesto en diversas latitudes, se pronuncia sobre la situación de la figura en el ordenamiento de varios países, proponiendo como solución para el caso chileno el recurso responsabilidad solidaria. Así, la mencionada colaboración -BARRíA (2011), pp. 151-183 - representa un interesante aporte en la línea de colmar la omisión legislativa nacional -bibliografía indicada en BARRÍA (2011), pp. 153-154- mediante el análisis del Derecho Comparado.
} 
el recurso a la responsabilidad solidaria; mientras que por otro, sistemas que siguen la técnica de una aproximación probabilística relativa a una responsabilidad proporcional. Lo anterior, nos permitirá pronunciarnos respecto de la manera de razonar el recurso resarcitorio en algunos países, tales como: Francia, Estados Unidos, Inglaterra, Austria, Holanda, o, incluso, en los Principios Europeos de la Responsabilidad Civil.

Pues bien, la solidaridad permite a la víctima perseguir el resarcimiento respecto de cualquiera de los supuestos agentes involucrados en el evento. Dicha solución ha sido objeto de razonables críticas, a nuestro juicio. Apreciamos que la regla de solidaridad es de extrema rigidez respecto de aquel demandado, que pretende hacer efectiva su acción de reverso en el patrimonio de los demás sujetos involucrados, toda vez que estos bien pueden ser insolventes o tal vez haber desaparecido a la época en que se ventilan judicialmente los hechos. Además, la incapacidad de uno de los demandados, que bien pudo no ser el causante del daño, por asumir el pago de la totalidad de la indemnización, puede derivar en una solicitud de declaración concursal. Por su parte, la solidaridad no parece tampoco ser la mejor alternativa para la víctima. En este sentido el profesor Albert Azagra M., sostiene:

"la solidaridad de deudores sólo puede ser entendida en clave pro damnato en relación con las víctimas presentes que demanden con anterioridad al agotamiento de los recursos de los deudores y aseguradoras aún solventes. El interés de estas víctimas prevalece sobre el de otras víctimas presentes y, en especial, sobre el de las futuras, cuyas expectativas de cobro se reducen significativamente"15.

Por otro lado, como se indicó, en el Derecho Comparado existen espacios en los que la proporcionalidad es considerada en la valoración del papel que ha observado el agente en las consecuencias dañosas de una acción u omisión. De aquí que alejándose de una suerte de determinismo propio del todo o nada, bien pueda ser considerado que un sujeto pueda ser más o menos responsable. Se asume que resulta muy poco realista que el juez pueda suponer de manera razonable la responsabilidad de un sujeto con un 100\% de certezas de su participación (para esquemas propios al sistema romano continental); de manera que el monto del resarcimiento al cual deba ser condenado tendrá que ser determinado dentro de una escala de lo probable a lo poco probable. En este escenario, la contingencia actual y la eventualidad de daños tardíos, es decir, aquellos que se presentan largo tiempo después de acaecido el evento del cual supuestamente derivan,

${ }^{15}$ AzAgra (2007), p. 4. 
obligarían al estudio de la proporcionalidad o probabilidad como herramienta integradora del defecto causal. En este contexto, dando por establecido que un daño puede provenir de un conjunto de causas (incluso de forma parcial por la conducta de la víctima), el mecanismo proporcional propone proyectar el instituto indemnizatorio en consideración al supuesto agente y al cálculo aproximativo del incremento del riesgo que su conducta significó respecto de la materialización de un daño. De aquí que pueda ser estudiada la proporcionalidad como un factor de restablecimiento de equilibrio.

Veremos que son amplios los criterios que permiten determinar la proporcionalidad en la participación de un daño. En este sentido, expondremos como la participación en el mercado ha sido considerada como unidad de aproximación probabilística. En efecto, nos pronunciaremos respecto de la teoría denominada market share liability ${ }^{16}$ la cual ha sido seguida excepcionalmente por algunos estados en USA. A su turno, la regla general de los países que han contemplado la posibilidad de recurrir a cálculos proporcionales en la determinación de la responsabilidad, sustentan el factor de atribución causal en virtud de cálculos científicos estructurados a la luz del riesgo y la contribución del agente en la materialización de este; así en Inglaterra ${ }^{17}$ y en Austria ${ }^{18}$. Por otro lado, no debemos olvidar que el recurso a la proporcionalidad en el Derecho Comparado es limitado, y, si bien este es reconocido en materias en las que parte de las causas tienen origen en la esfera de competencias de la misma víctima, como sucede en Austria, Holanda ${ }^{19}$ y es reconocido por los Principios Europeos de Responsabilidad Civil ${ }^{20}$, la aproximación ha sido objeto de cuestionamientos, los cuales materializados en ejercicios de analogía (Austria) o por expresas disposiciones legales (Holanda e Inglaterra ${ }^{21}$ ), se ha procurado mantener el statu quo de la solidaridad.

En fin, no debemos estimar que un sistema que sigue a la solidaridad como solución a escenarios de incertidumbre, no pueda presentar alternativas probabilísticas o viceversa. Ambas figuras, por regla general, se han constatado en varios de los países sobre los cuales nos referiremos.

1. El silencio legislativo manifestado por el Derecho francés de la responsabilidad civil, difiere del esfuerzo de la doctrina por brindar herramientas al problema de la indeterminación del agente. En efecto, detectamos en la academia la reciente conceptualización de la figura, expuesta en los siguientes términos:

\footnotetext{
${ }^{16}$ Sobre este punto, véase infra p. 221.

${ }^{17}$ Sobre este punto, véase infra, pp. 222-224.

${ }^{18}$ Sobre este punto, véase infra, p. 224.

${ }^{19}$ Ibid.

${ }^{20}$ Sobre este punto, véase infra, p. 225.

${ }^{21}$ Sobre este punto, véase infra, pp. 219-220.
} 
"el perjuicio es imputable a una sola persona indeterminada, entre varias determinadas. Esta situación puede ser denominada 'causalidad alternativa'. Una situación de causalidad alternativa existe entonces cuando, entre una pluralidad de actividades similares, cada una siendo suficiente para producir el daño respectivo, una sola (o algunas, pero no la totalidad) está efectivamente al origen del daño. La víctima, es en tal caso, capaz de probar que su daño proviene de uno de los hechos generadores, sin necesidad de demostrar cual, lo que prohíbe a priori una imputación de causalidad"22.

Este punto ha sido resuelto por los tribunales franceses condenándose de manera solidaria a los eventuales agentes, aun cuando uno de los condenados ningún daño ha producido. Siendo la anterior una solución antiguamente retenida por la Corte de Casación ${ }^{23}$, seguida, por su parte, por el Proyecto Catalá ${ }^{4}$, ha sido en la actualidad adoptada en juicios relativos tanto

a) a las consecuencias derivadas de la ingesta del medicamento Distilbène,

b) como respecto de infecciones nosocomiales o intrahospitalarias adquiridas en el seno de un establecimiento de salud.

Así las cosas, la víctima será indemnizada, sin que el sujeto activo pueda liberarse de su responsabilidad bajo el argumento del defecto probatorio del vínculo de causalidad.

a) En cuanto a la primera especie, habiéndose determinado que la ingesta in útero de la molécula había sido la causante de eventos de cáncer de útero o de vagina de las hijas de aquellas mujeres que habían consumido el medicamento Distilbène con el fin de evitar un parto prematuro, la Corte de Casación retuvo la responsabilidad solidaria de los laboratorios que comercializaron el producto. Lo anterior, en atención a la dificultad que significaba a la víctima, producto del transcurso de los años y de la pérdida de registro y de prescripciones médicas, determinar cuál había sido el distribuidor del fármaco que efectivamente causó el daño. Hacemos

${ }^{22}$ Quézel-Ambrunaz (2010), p. 1162. La denominación de "causalidad alternativa" ha sido recogida por destacados autores franceses. Así, Jourdain (2010), p. 567 y VineY (2010), p. 1247.

${ }^{23}$ Véase Aberkane (1958), p. 516.

${ }^{24}$ Art. 1348: "Lorsqu'un dommage est causé par un membre indéterminé d'un groupe, tous les membres identifiés en répondent solidairement sauf pour chacun d'eux à démontrer qu'il ne peut en être l'auteur". (Cuando un daño ha sido causado por un miembro indeterminado de un grupo, todos los miembros identificados responden solidariamente, salvo aquellos que puedan demostrar que no han sido los autores del mismo). 
presente además, que durante los procesos se había demostrado la negligencia evidente de los laboratorios en relación con no haber retirado del mercado el medicamento, puesto que científicamente estaba comprobada su nocividad. En fin, el peso de la prueba sería asignado, entonces, a los laboratorios en orden a probar que no se encontraban en el origen del daño, una prueba imposible. Lo anterior fue establecido por la Corte de Casación ${ }^{25}$ en septiembre de 2009, a condición de que la víctima estableciera su exposición al producto y el hecho de que este producto hubiera desencadenado el daño.

b) La segunda especie relativa a eventos de causalidad alternativa que ha motivado el pronunciamiento de tribunales franceses, corresponde a las infecciones intrahospitalarias o nosocomiales contraídas en el interior de establecimientos de atención médica. En este contexto no es novedad sostener que corresponde a la víctima rendir prueba de la infección ${ }^{26}$, la cual, incluso, puede ser demostrada mediante presunciones graves, precisas y concordantes $^{27}$. Sin perjuicio de lo anterior, bien puede la víctima haber sido tratada en dos o más establecimientos hospitalarios, sin que tenga la posibilidad de probar en cuál de ellos contrajo la infección. Respecto de este punto la Corte de Casación ${ }^{28}$ estableció: $^{-}$

"cuando la prueba de una infección nosocomial es aportada, pero ésta es susceptible de haber sido contraída en varios establecimientos de salud, pertenece a cada uno de ellos, respecto de los cuales su responsabilidad está involucrada, establecer que no está al origen de la infección".

Corresponde indicar que ambas figuras de causalidad alternativa a las que nos hemos referido, corresponden a especies que no se distancian entre ellas sino que levemente. De aquí que el razonamiento jurídico sea el mismo. Es así como en ambos casos la actividad de uno de los demandados en solidaridad no se encuentra en el origen del daño cuyo resarcimiento se reclama. Quizá podríamos indicar como única distinción, que respecto de las víctimas del Distilbène, ambos laboratorios ejercieron su industria de

${ }^{25}$ Suard con société UCB Pharma y otros (2009) y Ferrero y otros con société Novartis santé familiale y otros (2009). Cf. con Societé Pharma con X (2006) y Societé Pharma con $\mathrm{X}$ (2006). Las indicadas sentencias retuvieron la responsabilidad del laboratorio distribuidor del medicamento. Sin perjuicio de lo anterior, la Corte de Casación se pronunció respecto del incumplimiento en el deber de vigilancia, materializado en las consecuencias nocivas del fármaco).

${ }^{26}$ Belloti con Bouchet (2002).

${ }^{27}$ Mariotti con CPAM des Bouches-du-Rhône y otros (2008).

${ }^{28}$ Boultif y otros con CPAM des Bouches-du-Rhône y otros (2010). 
forma negligente puesto que no retiraron oportunamente del mercado el medicamento nocivo. Distinta es la situación relativa a la infección nosocomial, toda vez que uno de los establecimientos hospitalarios ha obrado de modo diligente, apegado al cuadro normativo. Así las cosas, la acción solidaria en contra de los laboratorios permite ser considerada como una sanción relativa a la culpa observada en la vigilancia y conocimiento de los avances científicos de la época, en una cuestión tan sensible como los efectos colaterales que un producto farmacéutico necesariamente va a producir. Sin perjuicio de lo anterior, y aun cuando uno de los centros hospitalarios en los hechos no sea el causante de la infección, no se considera justo hacer pesar sobre la víctima la incertidumbre relativa a la determinación efectiva del agente. No debemos olvidar que los demandados desarrollan una actividad a riesgo, creando o aumentando los mismos, pudiendo haber participado en la actividad de la cual derivó la infección. Luego, creemos pertinente hacer pesar sobre ellos, y no sobre la víctima, la carga probatoria relativa a su actuar diligente. Por último, a diferencia del Derecho francés en el que ha sido la jurisprudencia la que se ha encargado de proteger a las víctimas en eventos de indeterminación del agente, otros ordenamientos jurídicos europeos se han ocupado del problema en sus legislaciones. Así, el Código Civil alemán, en su artículo 830, o el Código 220 Civilholandés, en el artículo 99 del libro IV, contienen disposiciones de las que se desprende la responsabilidad solidaria a la que se exponen aquellos sujetos que pudieron haber causado el daño, sin que exista posibilidad de determinación científica al respecto ${ }^{29}$. Hacemos presente, a su turno, que el contencioso del Distilbène, también ha sido objeto de pronunciamientos en Holanda. El resultado ha sido idéntico al observado en Francia, rechazándose expresamente el recurso a la proporcionalidad y al market share liability, respecto del cual nos referiremos con posterioridad.

2. Por otra parte, el Derecho estadounidense se ha pronunciado sobre la causalidad alternativa (también denominada por William Prosser como la doublefault and alternative liability ${ }^{30}$, refundada recientemente por Mark Geistfeld bajo la tesis de la evidential grouping ${ }^{31}$ ) a través del Segundo Restatement of torts (1965). En efecto, el indicado trabajo considera en el $\$ 433 \mathrm{~B}(3)$ :

"Cuando la conducta de dos o más actores es ilícita, y se prueba que el daño ha sido causado al demandante por uno solo de ellos,

\footnotetext{
${ }^{29}$ Para una lectura general respecto de los Derechos alemán y holandés en la materia, BARRÍA (2011), pp. 163-165.

${ }^{30}$ Prosser (1971), pp. 270-271.

${ }^{31}$ Geistfeld (2006), pp. 454-477.
} 
pero hay incertidumbre en cuanto a cuál de ellos lo ha causado, la carga recae sobre cada uno de esos actores en lo relativo a probar que no han causado el daño"32.

Se debe hacer presente que la disposición transcrita fue adoptada bajo el criterio jurisprudencial expuesto en la sentencia Summers vs Tice (1948). Respecto de la indicada decisión, los hechos involucraron a tres cazadores de codorniz. Dos de los cazadores dispararon casi al mismo momento sus escopetas hiriendo al tercer cazador en uno de sus ojos. En atención a que los cazadores utilizaban la misma escopeta y la misma munición fue imposible determinar cuál de los cazadores había cometido el daño. Luego, el tribunal aceptó alterar la carga de la prueba de manera que fueran los cazadores quienes demostraran que no habían disparado el tiro causante del daño. A su turno, en caso en que los cazadores no pudieran exculparse serían condenados solidariamente como de hecho sucedió. Se lee en el fallo:

"Si consideramos la relativa posición de las partes y las consecuencias que seguirían en caso de requerir del demandante la atribución de la lesión en uno de los demandados, el requisito de la carga de la prueba se vería desplazado respecto de los demandados manifiestamente. Ambos son agentes, ambos han actuado negligentemente hacia el demandado. Generaron una situación en virtud de la cual la negligencia de uno de ellos produjo el daño. Por lo que cada uno debe excusarse a sí mismo, si puede. La víctima ha sido ubicada en la injusta posición de indicar cuál de los demandados ha causado el daño. Si uno de ellos puede escapar, el otro también, lo cual para la víctima sería irremediable"33.

Con posterioridad el Tercer Restatement of torts sobre Liability for Physical and Emotional Harm (2011) retuvo de nuevo la figura en estudio,

32 "Where the conduct of two or more actors is tortious, and it is proved that harm has been caused to the plaintiff byonly one of them, but there is uncertainty as towhichone has caused it, the burden is upon each such actor to provethat he has not caused the harm".

${ }^{33}$ Summers vs Tice (1948): "When we consider the relative position of the parties and the results that would flow if plaintiff was required to pin the injury on one of the defendants only, a requirement that the burden of proof on that subject beshifted to defendants becomes manifest. They are both wrong doers-both negligent toward plaintiff. They brought about a situation where the negligence of one of them injured the plaintiff, hence it should rest with the meach to absolve him self if he can. The injured party has been placed by defendants in the unfair position of pointing to which defendant caused the harm. If one can escape the other may also and plaintif fis remediless". 
separándose en vierta medida del tenor literal de la norma antes señalada. Básicamente, es exigido que sean demandados de forma conjunta todos aquellos que en atención de su conducta pudieron haber causado el daño. Se establece en el cuerpo normativo en el $§ 28$ (b):

"Cuando la víctima demanda a todos los múltiples actores y prueba que cada uno de ellos participa de la conducta ilícita que expone al demandante al riesgo de un daño, y que la conducta ilícita realizada por uno o más causó el daño del demandante, pero éste no puede razonablemente demostrar cuál o cuáles de los demandados causó el daño, la carga de la prueba que incluye tanto la producción como la persuasión, sobre la causalidad de los hechos, se desplaza a los acusados" ${ }^{34}$.

En fin, el criterio seguido por la sentencia enunciada así como por los restatements (segundo y tercero) envuelve la circunstancia evidente relativa a la dificultad para los demandados de probar que no han causado el daño, razonando de acuerdo al clásico criterio del "todo o nada" envuelto en una regla de responsabilidad solidaria.

El estudio del Derecho estadounidense, en este punto, nos conduce al 222 igual que en el escenario francés, al análisis de la solución jurisprudencial relativa a los daños causados por el medicamento DES. En el marco del indicado país fue adoptado un innovador mecanismo de responsabilidad proporcional, cuyo factor de determinación corresponde a la cuota que el laboratorio ocupa en el mercado farmacéutico pertinente. De aquí que bien pueda afirmarse que la parte del mercado utilizada por el industrial opere como un equivalente del porcentaje del daño a resarcir. En efecto, en el año 1980 la Corte Suprema de California retuvo la teoría de partes de mercado con el objetivo de fundar su decisión en el comentado fallo Sindell v Abbott Laboratories. En rigor, los jueces, reacios al mecanismo de la solidaridad, pero a su vez confusos respecto del mecanismo proporcional que planteaban $^{35}$, sostuvieron la tesis de presumir la causalidad de los laboratorios

34 "When the plaintiff sues all of multiple actors and proves that each engaged in tortious conduct that exposed the plaintiff to a risk of harm and that the tortious conduct of one or more of them caused the plaintiff'sharm but the plaintiff cannot reasonably be expected to prove which actor or actors caused the harm, the burden of proof, includin gboth production and persuasion, on factual causation is shifted to the defendants".

${ }^{35}$ Dobbs y Hayden (1997), p. 733 citados por Ruda (2003), p. 10. Hacemos presente que la formulación de la teoría de partes de mercado fue el fruto de un trabajo universitario redactado dos años antes del pronunciamiento de la sentencia, SHEINER (1978), pp. 963-1007. De aquí que su materialización a través de una sentencia requiera de una mayor maduración. Lo indicado provocó que la tesis fuera explicada por una posterior sentencia, Brown v. Superior Court (1988). 
involucrados, a menos que estos pudieran probar que no habían provocado el daño. En caso de imposibilidad de excusa por parte de alguno de los laboratorios, todos los supuestos agentes se consideran responsables de acuerdo con la proporción comercial que detentaban en el mercado, y en este sentido, de acuerdo con la probabilidad de haber producido el perjuicio en la víctima. Así, la condena de todos los integrantes del mercado conduce al resarcimiento íntegro del daño, como si hubiera sido identificado el causante del mismo ${ }^{36}$. Luego, si un laboratorio ocupaba el $45 \%$ del mercado farmacéutico (relativo al medicamento en cuestión) era titular del 45\% de posibilidades de haber causado el daño y, en definitiva, ser condenado a reparar un porcentaje equivalente en el daño sufrido por la víctima.

En virtud del indicado modelo de determinación causal, el cual se conoce como teoría de partes de mercado o market share liability, cuya formulación teórica ha sido desarrollada por la doctrina ${ }^{37}$, contribuye a que aquellas víctimas impedidas de probar científicamente cuál de los demandados está a la cabeza del daño -en circunstancias que existe certeza que uno de ellos ha sido el causante del mismo- pueda fundarse en el riesgo por estos creado para deducir una acción en responsabilidad. Con lo anterior se asegura que cada empresa pague según su implicación causal en el universo de víctimas.

Es importante destacar que la teoría de las partes de mercado no ha logrado un poder de convicción incuestionable y ha sido rechazada por las jurisdicciones de diversos estados en USA, tanto respecto de contenciosos en los que el DES se encontraba involucrado ${ }^{38}$, como respecto de otro tipo de productos $^{39}$. La falta de consenso expuesta ha motivado al Tercer Restatement (1998 § 15 c y $2011 \S 28$ c) a manifestar la voluntad de:

“dejar al desarrollo del Derecho la cuestión relativa a, si dados los factores apropiados, una regla de responsabilidad proporcional debería adoptarse" ${ }^{" 40}$.

Hacemos presente que no registramos sentencias que hayan acogido la teoría sobre partes de mercado fuera de Estados Unidos. De hecho, en

${ }^{36}$ EPSTEIN (1985), p. 1380.

${ }^{37}$ Ruda (2003), pp. 6-10; Nick (2008-2009), pp. 228-232; Rostron (2004-2005), pp. 152-215.

${ }^{38}$ En este sentido Oliphant (2011), p. 1603.

${ }^{39}$ Smith v. CutterBiological, Inc., A Division of Miles Inc., 72 Haw. 416 (1991). Se intentó aplicar la teoría de las partes de mercado a un caso de sangre contaminada con VIH).

40 “...leaves to developinglaw the question of whethergiven the appropriatefactors, a rule of proportionateliabilityshouldbeadopted". 
Francia un reciente fallo de la Corte de Apelaciones de París ${ }^{41}$ siguió la tesis de la solidaridad para condenar a un laboratorio, no obstante ocupar el 2,3\% del mercado a la época de los hechos. La escasa participación en el mercado del laboratorio en cuestión ha motivado que la tesis de la solidaridad sea cuestionada por parte de la doctrina francesa ${ }^{42}$.

3.- El ordenamiento jurídico inglés se ha pronunciado respecto del problema que nos ocupa, primero desde un punto de vista judicial y luego desde uno legislativo. Indicamos en este punto que el Derecho inglés no registra jurisprudencia condenatoria en el capítulo de juicios de caza en el ámbito de la Cámara de los Lores, por lo que las soluciones en esta materia por el máximo tribunal son relativamente recientes. La contingencia se ha radicado respecto de los eventos de mesotelioma, tumor ubicado en la pleura, enfermedad derivada de la exposición al asbesto. Bien puede afirmarse hoy día que la exposición a las fibras de asbesto produce graves daños a la salud. Sin perjuicio de lo anterior, resulta desde la óptica científica imposible determinar quien es el responsable del perjuicio cuando el afectado se ha visto expuesto a varias fuentes nocivas. En importantes sentencias la Cámara de los Lores se ha hecho cargo del problema. Es así como en junio de 2002, en el juicio Fairchild con Glenhaven Funeral Services Ltd. and others, el máximo tribunal redujo los estándares probatorios de la causa entre hecho generador y daño, dando lugar a las pretensiones de los trabajadores afectados, aun cuando no se pronunció, sobre si la responsabilidad que recaía respecto de los empleadores involucrados debía ser estimada como solidaria o proporcional, puesto que sobre esto último no había sido requerido su pronunciamiento. En los hechos, las viudas de dos dependientes y un trabajador enfermo gravemente demandaron a los empleadores respectivos. En segunda instancia se desestimaron las pretensiones de los demandantes, aun cuando en primera instancia se había dado lugar a la reparación solicitada por el obrero víctima del cáncer. En definitiva, la Cámara de los Lores, condenó a los agentes involucrados, no obstante la incertidumbre científica, principal obstáculo del litigio. Se desprende de lo expuesto por lord Alan Rodger que la condena se justifica en atención a que producto de la latencia de la enfermedad y a sus dificultades etiológicas no habia sido posible determinar donde había sido contraída la enfermedad según la aplicación de la balanza de probabilidades ${ }^{43}$. A su turno, lord Thomas Bingham, fundó la responsabilidad de todos los demandados en

${ }^{41}$ Marie-Elise X y otros con USB Pharma y otros (2012).

${ }^{42}$ Ferey (2013), p. 2709.

43 "Because of the current state of medical know ledge about the aetiology of mesothelioma, it was impossible for the claimants to proveon the balance of probabilities that themen's illness had been triggered by a fibre or fibres inhaled while working with any particular employer and, more especially, while working with the particular defendants whom they had sued" (cons. 124). 
relación con que estos habían contribuido en la creación del riesgo del cáncer que, en definitiva, se contrajo, estimándose que la aparente injusticia en la atribución de una causalidad no probada científicamente era compensada con el hecho de haber expuesto a los trabajadores al asbesto, negando una reparación a las víctimas ${ }^{44}$. Siendo estimado por lord Leonard Hoffman, además, que insistir en una determinación tradicional de la causalidad, para éste y otros casos, podría permitir habilitar al agente a exponerse sin temor de su parte a una condena por responsabilidad civi $l^{45}$.

Cuatro años más tarde, en mayo de 2006, la sentencia Barker con Corus fue pronunciada por la Cámara de los Lores, respecto de varios casos de mesotelioma por exposición a fibras de asbesto. Sería esta sentencia una oportuna herramienta para conocer el pronunciamiento de la Cámara sobre el resarcimiento solidario o proporcional que debía ser requerido de los demandados. En los hechos, tres personas habían fallecido producto de exposición al material, mientras que en primera como en segunda instancia los tribunales habían condenado solidariamente a los empleadores demandados, el máximo tribunal por cuatro votos contra uno, estimó que la condena resarcitoria debía ser dividida en razón de la cuota por incremento del riesgo en que cada una de los agentes había participado. La aproximación proporcionalfue defendida, entre otros, por lord Leonard Hoffman, quien expuso:

"En mi opinión, la atribución de responsabilidad, de acuerdo con el grado relativo de la contribución a la posibilidad de que la enfermedad se contraiga sería suavizar la aspereza de la justicia, que crea una regla de responsabilidad solidaria. El acusado configura las características de un agente, es cierto, y no se le debe permitir eludir su responsabilidad por completo, pero no debe ser responsable por más que el daño que causó y, puesto que este es un caso en el que la ciencia sólo puede ocuparse de las probabilidades, la ley debe aceptar esa posición y atribuir la responsabilidad de acuerdo a las probabilidades" ${ }^{\prime 6}$.

44 "Inhalation of asbestos dustcarries a risk of mesothelioma. That is one of the very risks from which an employer's duty of care is intended to protect employees. Tragically, each claim an tacquired this fatal disease from wrongful exposure to asbestosdust in the course of his employment. A former employee's inability to identify which particular period of wrongful exposure brought about the onset of his disease ought not, in all justice, to preclude recovery of compensation" (cons. 41).

45 "In these circumstances, a rule requiring proof of a link between the defendant's asbestos and the claimant's disease would, with the arbitrary exception of single-employer cases, empty the duty of content. If liability depends upon proof that the conduct of the defendant was a necessary condition of the injury, it cannot effective lyexist. It is however open to your Lordships to formulate a different causal requirement in this class of case". (cons. 62).

46 "In my opinion, the attribution of liability according to the relative degree of contribution to the chance of the disease being contract edwould smooth the roughness of the 
El criterio expuesto, menos conveniente a las víctimas, por cierto (hacemos presente que algunas de las empresas eran insolventes a la época de la resolución), motivó una fuerte presión ciudadana que finalmente provocó el pronunciamiento legislativo materializado en la Compensation Act Bill 2006. De la ley puede ser leído:

"El responsable asume una responsabilidad solidaria por el meotelioma sufrido por la víctima si cuatro condiciones se cumplen: (a) Alguien (el responsable) causó o permitió negligentemente o con infracción de un deber legal que otra persona (la víctima) estuviera expuesta al asbesto. (b) La víctima ha contraído mesotelioma como consecuencia de la exposición al asbesto. (c) Debido a la naturaleza del mesotelioma y al estado de los conocimientos médicos y científicos, no es posible determinar con certeza si fue la exposición a la que se hace referencia en la letra (a) u otra exposición la que causó la enfermedad de la víctima, y (d) El responsable lo es de un ilícito civil (tort), como consecuencia de la exposición a la que se hace referencia en la letra (a) y por el daño causado a la víctima por la enfermedad (ya sea por haber incrementado materialmente el riesgo o por cualquier otra razón) ${ }^{\wedge 47}$.

En esta ley se consagra la responsabilidad solidaria de los agentes involucrados en eventos de enfermedades derivadas de la exposición al asbesto, dándose, de esta manera, razón a los tribunales que habían interpretado que era una regla de solidaridad la que debía ser aplicada según lo resuelto por Fairchild con Glenhaven Funeral Services(2002).

4. La aproximación proporcional también ha sido observada por la Corte Suprema holandesa en materia de asbesto, siguiendo las reflexio-

justice which a rule of joint and several liability creates. The defendant was a wrongdoer, it is true, and should not beallowed to escape liability altogether, but he should not be liable for more than the damage which he caused and, since this is a case in which science can deal only in probabilities, the law should accept that position and attribute liability according to probabilities" (cons. 43).

47 "A responsible person has a joint and several liability for mesothelioma suffered by a victim if four conditions are satisfied: (a) a person ('the responsible person') has negligently or in breach of statutory duty caused or permitted another person ('the victim') to be exposed to asbestos, (b) the victim has contract edmeso the lioma as a result of exposure to asbestos, (c) because of the nature of mesothelioma and the state of medical science, itis not possible to determine with certainty whe therit was the exposurementioned in paragraph (a) or another exposure which caused the victim to becomeill, and (d) the responsible personis liable in tort, by virtue of the expo sure mentioned in paragraph (a), in connection with damage caused to the victim by the disease (whether by reason of having material lyincreased a risk or for anyother reason)". 
nes expuestas por la Cámara de los Lores en el litigio Barker con Corus UK Ltd (2006). Así, en Karamus con Nefalit (2006), fueron consideradas las posibles causas que figuraban dentro del ámbito de competencia del demandante. En los hechos, el litigio versó sobre un caso de cáncer al pulmón (distinto del mesotelioma, y con ello, de menor atribución causal al asbesto) cuyo origen puede deberse a una pluralidad de factores. Luego, no necesariamente producto del contacto profesional con partículas de asbesto. En los hechos se acreditó la condición de fumador de la víctima y su predisposición genética como supuestos factores causantes del tumor. En definitiva, se retuvo la responsabilidad del demandado, pero rebajada en la proporcionalidad atribuida a la participación de la conducta de la víctima en el daño. Se estimó que aun cuando es injustificable que el empleador hubiere incumplido una norma legal producto de la cual expuso al empleador a partículas de asbesto, igualmente no es justo exponer al empleador a la condena del resarcimiento íntegro del daño, en circunstancias de la importante probabilidad que sea el mismo enfermo quien esté a la cabeza del mal sufrido ${ }^{48}$.

5. Con el fin de dar solución al problema de la causalidad alternativa en Austria, se ha defendido la aplicación analógica del § 1302 del $A B G B$ del que se desprende una solución solidaria ${ }^{49}$. Sin perjuicio de lo anterior, la doctrina ha propuesto una respuesta flexible respecto de aquel caso en que la posible participación de uno de los agentes en el desenlace dañoso fuera muy menor. El núcleo de la figura obedece a atribuir un grado de responsabilidad mayor a quien, en su conducta, representa un grado concreto de peligrosidad. Luego, no se considera justo que sea medido con la misma vara que respecto de aquel supuesto agente cuya conducta no representa más que un riesgo potencial ${ }^{50}$. El reconocimiento jurisprudencial del mecanismo probabilístico, por su parte, se detecta en Austria respecto de figuras de las que puede estimarse que la conducta de la víctima posiblemente ha contribuido de manera significativa en el daño, mediante un ejercicio de analogía del $§ 1304 \operatorname{del} A B G B$, disposición que ordena la disminución de la valoración del daño en circunstancias en que la víctima haya contribuido en él, en atención de su conducta culposa. La doctrina reseña haciendo referencia a un pronunciamiento de la Corte Suprema del año 1995 (4 Ob 554/95 JBl 1996,181) relativo al nacimiento y parálisis cerebral de un niño ${ }^{51}$. En los hechos, la parálisis puede ser atribuida tanto a un defecto en la placenta de la madre, producida por un descui-

\footnotetext{
${ }^{48}$ Un estudio más detallado puede leerse en SoвczaK (2009), pp. 1167-1170.

${ }^{49}$ Oliphant (2010), p. 182.

${ }^{50}$ Oliphant (2011), p. 1626.

${ }^{51}$ Oliphant (2010), p. 183.
} 
do culpable de su propio estado de gravidez; como al cordón umbilical enrollado en el cuello del niño provocando asfixia. En definitiva, frente a la ausencia de prueba concluyente respecto de las dos posibles causas, el tribunal resolvió estimando que el daño debía ser asumido por partes iguales entre ambas partes del litigio.

6. En fin, el problema de la proporcionalidad también ha sido absorbido por los Principios Europeos de Responsabilidad Civil ${ }^{52}$. En este trabajo, particularmente en el capítulo dedicado a la causalidad ${ }^{53}$, se considera e específico el recurso a la conditio sine qua non como regla de base en la determinación del vínculo. Sin perjuicio de lo anterior, respecto de aquellas situaciones en las que no es evidente demostrar la causalidad, los principios contemplan soluciones. Dichas respuestas están enfocadas respecto de tres escenarios de irresolución; causalidad alternativa, potencial e incierta. Respecto de la causalidad potencial no nos pronunciaremos, pues escapa, su comentario, a nuestro estudio. Por su parte, en materia de causalidad alternativa, el artículo 3:103 (1) contempla el recurso de la responsabilidad proporcional, en atención a la probabilidad de participación de cada uno de los miembros del grupo en la concretización del riesgo. Ordena la disposición:

“...se considera que cada actividad es causa en la medida correspondiente a la probabilidad de que pueda haber causado el daño a la víctima”.

La proporcionalidad, a su turno, es también enfocada por los principios, respecto de situaciones caracterizadas por existir una pluralidad de víctimas, y la duda en que se haya causado daño a una víctima concreta, siendo probable que se haya causado daño a todas las víctimas, en este caso el art. 3:103 (2) establece:

"se considera que la actividad es causa del daño sufrido por todas las víctimas en proporción a la probabilidad de que pueda haber causado el daño a una víctima concreta”.

Por último, se comprenden en el trabajo normativo, particularmente en el art. 3:106, la figura concerniente a las causas inciertas vinculadas a la esfera de la víctima. En este punto, la víctima debe asumir el daño

${ }^{52}$ Para una aproximación general sobre los Principios Europeos de Responsabilidad Civil: Martín Casals (2005).

${ }^{53}$ Capítulo 3: Relación de causalidad. 
"en la medida correspondiente a la probabilidad de que pueda haber sido causada por una actividad, acontecimiento o cualquier otra circunstancia perteneciente a su propia esfera”.

Diversas observaciones pueden ser formuladas respecto de la técnica proporcional. Desde una perspectiva favorable, bien sabemos que en materia de causalidad alternativa condenar a todos los demandados a fin de obtener una indemnización corresponde a una ficción. Lo dicho, pues solo uno o varios, pero no todos los involucrados en el litigio, son los causantes del daño. Es por esto que un criterio de repartición probabilista del daño permitiría reducir el error en el que obligadamente debe incurrir el juez al liberar de una parte de responsabilidad a quien ha causado el perjuicio, asignándole aquel porcentaje a quien no ha intervenido en el desenlace dañoso. En este punto el profesor francés Samuel Ferey, señala:

"Compartir en igualdad la carga de la deuda entre los dos laboratorios conduce a equivocarse fuertemente (...). la regla de repartición donde las partes de cada uno son alineadas según sus probabilidades respectivas de haber causado el daño, provoca errores más débiles y domina en consecuencia la regla de división igualitaria (...)”54.

Por su parte -respecto del recurso a la teoría de las partes de mercadopuede ser entendido como una solución económicamente efectiva. Lo indicado, pues el laboratorio que detenta un porcentaje superior al 50\% del mercado deberá ajustar su eventual responsabilidad en relación con la magnitud del riesgo que ha creado, sin beneficiarse de una condena indemnizatoria equivalente a la mitad del daño (en el evento en que hubieran dos laboratorios involucrados).

Desde una perspectiva crítica, expondremos algunos argumentos, sobre los cuales bien puede sostenerse un rechazo de este modelo de reflexión causal.

- En primer lugar, criticando al modelo de la teoría de las partes de mercado, se desprende de lo expuesto por el profesor Hernán Corral T. ${ }^{55}$ que en ciertas situaciones no es posible determinar con claridad la extensión del espacio económico en el cual se desenvuelve un mercado determinado, ni tampoco cual es el porcentaje de participación de una empresa en él.

- En segundo lugar, si bien una responsabilidad proporcional podría ser retenida por un sistema de causalidad cierta y directa al 100\%

${ }^{54}$ Ferey (2013), p. 2709.

${ }^{55}$ Corral (2011), p. 87. 
o de alta probabilidad, pues el mecanismo vendría a absorber el espacio imaginario entre lo probado y lo no probado; no nos persuadimos de su manera de actuar en un modelo basado en una escala de probabilidades.

Lo anterior, pues en el indicado esquema, la indemnización es plena en el evento de una demostración igual o superior al 50\% que una determinada circunstancia sea probablemente la causa de un daño. Luego, aceptar el sistema de responsabilidad proporcional en este ámbito, implicaría dos consecuencias:

- aceptar una indemnización proporcional respecto de causas probables inferiores al $50 \%$

- rebajar las indemnizaciones plenas de las víctimas, respecto de causas probables fluctuantes entre el 50 y el 100\%.

- En tercer lugar, estimamos que la aproximación probabilística pierde fuerza si nos detenemos en la proporcionalidad y su trascendencia jurídico-causal. La verdad es que no nos convence la idea que la probabilidad permita cuantificar el rol causal entre hecho generador y daño. Nosotros creemos que la proporcionalidad es importante, en el entendido que debe ser utilizada más bien como elemento de calificación.

Estimamos categóricas las palabras del profesor Christophe Quézel-Ambrunaz, quien enseña: "un hecho no es causa de un daño porque lo vuelva probable, sino porque lo explica" ${ }^{56}$.

- Por último, en cuarto lugar, hacemos nuestras las palabras del autor español Albert Ruda G. quien reconociendo que la regla del todo o nada bien puede ser cuestionable respecto del devenir tecnológico actual y desde un punto de vista pragmático el recurso proporcional podría conducir a resultados aceptables

"una cosa es la simpatía o compasión que puedan merecer las víctimas desde un punto de vista moral, y otra muy distinta la capacidad de un sistema preestablecido de responsabilidad civil para darles una respuesta adecuada; una cosa es que una regla jurídica tenga limitaciones, y otra que deba sustituirse más o menos acríticamente por otra distinta" ${ }^{57}$.

Ahora bien, se desprende del comentario apuntado del profesor Albert Ruda G. que el régimen del "todo o nada" derivado de la solidaridad presenta limitaciones, lo cual estimamos como efectivo. Como mecanismo

${ }^{56}$ Quézel-Ambrunaz (2010), p. 307.

${ }^{57}$ Ruda (2003), p. 13. 
de solución frente a lo expuesto, el citado autor Albert Azagra M. trae a colación una de las vías ${ }^{58}$ propuestas por el American Law Institute -en virtud del Tercer Restatement of torts, sobre Apportionment of Liability (2000) - con el objetivo de sortear el problema de múltiples causantes de un daño indivisible. Dicha alternativa la denomina mecanismo de "solidaridad corregida”, a la cual nosotros adherimos. En rigor, la solución pretende que en eventos de insolvencia o inmunidad de uno o más codeudores, sean repartidas las cuotas de éstos entre todos los presentes en el proceso, incluida la víctima; la disposición establece:

“el tribunal reasigna la porción incobrable de los daños y perjuicios a las demás partes, incluido el demandante, en proporción de una responsabilidad comparativa asignada a las otras partes".

Lo anterior, salvo que los codeudores sean dolosos, no hayan protegido debidamente a la víctima de un hecho dañoso doloso, hayan actuado concertados o respondan por hecho ajeno ${ }^{59}$. Concluyendo el profesor Albert Azagra sostiene:

"la solidaridad corregida es una solución ecuánime en supuestos de incertidumbre causal. Permite a la víctima el acceso a la indemnización, pero reparte el riesgo de insolvencia entre demandantes y demandados y, en consecuencia, preserva parte de los recursos disponibles" ${ }^{60}$.

Por nuestra parte, reiteramos el asentimiento expresado a la fórmula indicada. El efecto, el ejercicio de la "solidaridad corregida" permite evitar que el restablecimiento del equilibrio no sea más que una ilusión en situaciones en las que la persecución de uno de los codeudores sea imposible, sin alejarse de una solución jurídica acorde con el espíritu de nuestra legislación.

${ }^{58}$ Azagra (2007), p. 5.

${ }^{59} \mathrm{El}$ texto original dispone: § C 21:“(a) Except as provided in Subsection (b), if a defendant establishes that a judgment for contribution cannot be collected fully froman other defendant, the court real locates the uncollectible portion of damages to all other parties, including the plaintiff, in proportion to the percentages of comparative responsibility assigned to the other parties. (b) Reallocation under Subsection (a) is not available to any defendant subject to joint and several liability pursuant to 12 (intentional tort feasors) or $\S 15$ (persons acting in concert). Any defendant legally liable for the share of comparative faultassigned to another person pursuant to $\S 13$ (vicarious liability) or $\S$ 14 (tort feasors who fail to protect the plaintiff from the specific risk of an intentional tort) may not obtain reallocation of the imposed by those Sections".

${ }^{60}$ Azagra (2007). 


\section{EL PROBLEMA DE LA INDETERMINACIÓN JURÍDICA}

\section{DE LA VÍCTIMA}

Es de simple comprensión que el problema de la incertidumbre causal sea ubicado respecto de aquella contingencia que impide que todos los presupuestos de la cadena causal sean conocidos. Así, por ejemplo, ninguna dificultad representa que la sangre que se proporcionó al enfermo mediante la transfusión estuviera contaminada, pues el dador padecía VIH. En esta situación, la determinación del vínculo es sencilla y se traduce en una mera imputación. En cambio, si dentro de los componentes del vínculo causal no todos los elementos son conocidos como, por ejemplo, si es imposible determinar cuál de los lotes de sangre fue el contaminado, la víctima resulta jurídicamente indeterminada ${ }^{61}$. Para remediar lo anterior, no quedará otra alternativa que acudir a algún mecanismo que permita inferir la causalidad que mediante un ejercicio científico no puede ser establecida. Estimar lo contrario corresponde a una traducción jurídica de indefensión.

Diversos ordenamientos jurídicos permiten invertir el peso de la prueba desde el demandante al demandado en ciertas circunstancias. De aquí, que aun cuando varias legislaciones requieran una prueba cierta y directa del nexo causal, como en Chile, España o Francia, por ejemplo, 232 esta certeza puede ser establecida por la evidencia constatable entre la conexión del hecho generador y el daño. Por otra parte, la citada profesora Lara Khoury, nos enseña que tribunales regidos por el Civil Law como del Common Law observan en sus razonamientos una clara distinción entre una causalidad científica y una causalidad jurídica o legal ${ }^{62}$. Respecto de esta última especie, la inferencia del nexo no requiere un riguroso examen matemático o científico para justificar la conexión con el hecho generador de la responsabilidad. Lo indicado podemos explicarlo según lo enseñado por el decano René Savatier, entre otros, de quienes se desprende que la causalidad puede ser presumida tomando en consideración especificos elementos de hecho, en el sentido en que no hay otra explicación para el daño que la culpa o la creación del riego del demandado ${ }^{63}$. Pues bien, consideramos oportuno referirnos a la técnica seguida por diversos ordenamientos jurídicos, en lo que tiene relación con la incertidumbre científica desde la perspectiva de la víctima indeterminada jurídicamente. Nos pronunciaremos de forma breve al caso francés, alemán, quebequés y estadounidense.

${ }^{61}$ Cour de Cassation, Ordre des avocats au Conseil d'État et à la Cour de cassation, IHEJ, EN3S, CHEA (2008), p. 179.

${ }^{62}$ Khoury (2006).

${ }^{63}$ Savatier y otros (1956), p. 319. 
1. El Derecho de la responsabilidad civil en Francia se ha recurrido tanto a:

a) presunciones legales

b) como de hecho.

a. En cuanto a presunciones legales el tema ha sido abordado respecto de la contaminación del VIH o de la hepatitis $\mathrm{C}$ a causa de una transfusión sanguínea. Respecto de la contaminación con el VIH, el legislador, según se desprende del inciso primero del artículo L.3122-2 ${ }^{64}$ del Código de la Salud Pública, ha establecido que a la víctima le basta justificar que padece la enfermedad y que ha recibido una transfusión sanguínea, para ser amparado por una presunción de responsabilidad. Por su parte, pertenecerá a la ONIAM de establecer que no hay causalidad entre la transfusión y la contaminación o, al menos, que existe duda seria. La víctima, por consiguiente, no debe probar una causalidad científica entre la relación de la enfermedad y el hecho de la transfusión. Hacemos presente, según se ha resuelto, que el comportamiento o conducta sexual del afectado no presenta el mérito para desvirtuar la presunción ${ }^{65}$. Llegándose a afirmar que solo la prueba de no contaminación de todas las unidades de sangre, podría privar de resarcimiento ${ }^{66}$. Respecto de la contaminación transfusional con el virus de la hepatitis $\mathrm{C}$, la solución es similar a la referida anteriormente. Así se desprende del artículo 102 de la ley $\mathrm{N}^{0}$ 2002-303 del 4 de marzo de 2002, relativa a los derechos de los enfermos y a la calidad del sistema de salud ${ }^{67}$.

64 "Dans leur demande d'indemnisation, les victimes ou leurs ayants droit justifient de l'atteinte par le virus d'immunodéficience humaine et des transfusions de produits sanguins ou des injections de produits dérivés du sang". (En su demanda de indemnización, las víctimas o sus causahabientes deben justificar el daño derivado del virus de inmunodeficiencia humana y las transfusiones de productos sanguíneos o de inyecciones de productos derivados de la sangre).

${ }^{65}$ Senft con société Axa France y otros (2007).

${ }^{66}$ Sahraoui con FITH contaminés par le VIH (2005).

67 "En cas de contestation relative à l'imputabilité d'une contamination par le virus de l'hépatite $\mathrm{C}$ antérieure à la date d'entrée en vigueur de la présente loi, le demandeur apporte des éléments qui permettent de présumer que cette contamination a pour origine une transfusion de produits sanguins labiles ou une injection de médicaments dérivés du sang. Au vu de ces éléments, il incombe à la partie défenderesse de prouver que cette transfusion ou cette injection n'est pas à l'origine de la contamination. Le juge forme sa conviction après avoir ordonné, en cas de besoin, toutes les mesures d'instruction qu'il estime utiles. Le doute profiteau demandeur". (Que en caso de contestación relativa a la imputabilidad de una contaminación por el virus de la hepatitis $\mathrm{C}$ anterior a la entrada en vigor de la ley, el demandante debe aportar la prueba de los elementos que permitan presumir que esta contaminación tiene por origen una transfusión de sangre o una inyección de medicamentos derivados de la sangre. A la vista de estos elementos corresponde a la parte demandada aportar la prueba que la transfusión o inyección no 
b. En cuanto al recurso a las presunciones de hecho, cabe destacar que el artículo 1353 del Code $e^{68}$ habilita al juez para retener este mecanismo de reflexión jurídica basándose en hechos graves, precisos y concordantes. Este razonamiento fue seguido en el contencioso sobre el contagio con el $V I H$ sufrido por el responsable en retirar basuras del depósito de desechos de un centro médico, producto de la herida provocada por una aguja sobresaliente $^{69}$. En definitiva, se retiene la responsabilidad del establecimiento al no existir otras posibilidades de contagio, en otras palabras, al no pertenecer la víctima a un grupo de personas expuesto al contagio de la enfermedad. El recurso a las presunciones de hecho también se ha verificado respecto de eventos de esclerosis en placas surgidos como consecuencia de la aplicación de la vacuna contra la hepatitis B. En efecto, constatamos como de una estricta identificación de la causalidad jurídica con la causalidad científica, los tribunales franceses han separado aguas infiriendo la causalidad sin necesidad de exigir un vínculo científicamente demostrado. Es así como en el año 2003 fue exigida por la Corte de Casación $^{70}$ la prueba científica entre esclerosis y vacuna. Desestimándose en definitiva la resolución del Tribunal de Alzada en la que se acogió la determinación del vínculo mediante presunciones ${ }^{71}$. La Corte de Apelaciones estimó que la asociación entre enfermedad y producto no puede ser excluida de forma 234 cierta, puesto que el demandante estaba en perfecto estado de salud hasta la primera inyección de la vacuna, que existe concordancia entre la vacuna y la aparición de la enfermedad igualmente constatada en otros enfermos, y que no hay en el caso del demandante, ninguna otra causa que haya motivado la enfermedad. En fin, la Corte de Casación declaró, en definitiva:

constituye el origen de la contaminación. El juez forma su convicción después de haber ordenado, en caso de necesidad, todas las medidas de instrucción que estime útiles. La duda beneficia al demandante).

68 "Les présomptions qui ne sont point établies par la loi, sont abandonnées aux lumières et à la prudence du magistrat, qui ne doit admettre que des présomptions graves, précises et concordantes, et dans les cas seulement où la loi admet les preuves testimoniales, à moins que l'acte ne soit attaqué pour cause de fraude ou de dol". (Las presunciones que no son establecidas por la ley, son entregadas a las luces y a la prudencia del magistrado, que no debe admitir que presunciones graves, precisas y concordantes, y en los casos solamente en donde la ley admite las pruebas testimoniales, a menos que el acta no sea impugnada por causa de fraude o de dolo)

${ }^{69}$ Société la Médicale de France con syndicat des copropriétaires avenue de saxe à paris $15^{\mathrm{e}}(2005)$.

${ }^{70}$ Sas laboratoire Smithkline/Morice (2003). "En se déterminant ainsi, sans tirer les conséquences légales de ses constatations desquelles il résultait que le défaut du vaccin comme le lien de causalité entre la vaccination et la maladie ne pouvaient être établis, la Cour d'appel a violé les articles 1147 et 1382 du Code civil".

${ }^{71}$ Smithkline / Morice (2001): CA Versailles, № 98/06839, Juris Data: 2001-187652; Véase Jourdain (2001), p. 891. 
"que decidiendo así, sin observar las consecuencias legales de las constataciones, de las cuales resultaba que el defecto de la vacuna como el vínculo de causalidad entre la vacuna y la enfermedad no podían ser establecidas, la Corte de Apelaciones violó los artículos 1147 y 1382 del Código Civil”.

Separándose del criterio antes establecido el máximo tribunal francés, en el 22 de mayo de 2008, volcó su jurisprudencia en favor de las víctimas y de la determinación de la causalidad mediante el camino de las presunciones, en virtud de una serie de sentencias ${ }^{72}$. En efecto, la Corte de Casación reprochó de los fallos de las Cortes de Apelaciones respectivas

"haber decidido en referencia a una aproximación probabilística deducida exclusivamente de la ausencia del vínculo de científico y estadístico entre la vacunación y el desarrollo de la enfermedad, sin investigar si los elementos de prueba que le habían sido presentados constituían o no presunciones graves, precisas o concordantes del carácter defectuoso de la vacuna litigiosa, como del vínculo de causalidad entre un eventual defecto y el daño sufrido"73.

Así, en caso de la retención de la presunción, corresponderá a los laboratorios demostrar que el contagio se verificó por otra causa o la inocuidad de la vacuna. Aplicándose en rigor una carga probatoria dinámica tributaria de una suerte de pragmatismo jurídico ${ }^{74}$, pues "se hará pesar sobre quien tenga la mejor aptitud a la prueba el riesgo ligado a la duda científica" ${ }^{\text {" }}$.

2. Por su parte, el Derecho alemán, como es normal, asigna el peso de la prueba al demandante. Además, la producción probatoria debe sujetarse a los estrictos márgenes de convicción judicial exigidos por el Código de Procedimiento Civil (Zivil prozessordung) ${ }^{76}$. Sin perjuicio de lo an-

${ }^{72}$ Beaulaton c/ CPAM de la Sarthe etautre (2008); Gacem c/ Razongles et autres; Consorts Fageolle c/ SociétéLaboratoiresGlaxosmithkline et autres y Signerin c/ Société Aventis Pasteur MSD et autre.

73 “...suit qu'en se déterminant ainsi, en référence à une approche probabiliste déduite exclusivement de l'absence de lien scientifique et statistique entre vaccination et développement de la maladie, sans rechercher si les éléments de preuve qui lui étaient soumis constituaient, ou non, des présomptions graves, précises et concordantes du caractère défectueux du vaccin litigieux, comme du lien de causalité entre un éventuel défaut et le dommage".

${ }^{74}$ RADÉ (2008a), No 5.

${ }^{75}$ RADÉ (2008b), No 25.

${ }^{76} \S 286(1)$ : "The court shall decide atits discretion, by taking in to account the entire substance of the hearings and the result of anyevidence taken, whe ther an allegation regarding the facts should beregarded as true or untrue". (El tribunal someterá a su 
terior, en materias sensibles como las relacionadas con la responsabilidad médica, contenciosos en los que debe materializarse la igualdad de armas $^{77}$ garantizada por el artículo 103 de la Constitución ${ }^{78}$, diversos aspectos contribuyen a que la prueba de la víctima pueda ser rendida de manera más expedita, bajo una perspectiva más favorable. En efecto, contribuye a esta visión el carácter inquisitorio del proceso alemán, en cuya virtud la convicción judicial no se adquiere exclusivamente en razón de lo probado o no por las partes, sino que también mediante el informe elaborado por peritos neutrales designados por el tribunal con el fin de pronunciarse sobre la materia del contencioso. Por su parte, se ha hecho presente que el razonamiento del juez bien puede ser observable si se ajusta a una errónea apreciación de los hechos por parte del informe pericial. Es por lo anterior que se ha sostenido, que mediante el examen del historial médico del paciente -el cual, si bien puede no demostrar la existencia de una negligencia evidente por parte del médico- puede desprenderse la observancia de errores que de forma individual no resultan determinantes, pero globalmente justificantes del desenlace o estado del enfermo ${ }^{79}$.

Junto con lo indicado, si bien el Derecho alemán respecto de aquellas materias en las que es desde el punto de vista científico imposible demostrar la conexión causal entre el daño y hecho generador, pues éste puede ser 236 una consecuencia de la enfermedad misma que motivó la intervención médica y no siempre deberse a la acción u omisión del profesional, ha razonado recurriendo al ejercicio de la balanza de probabilidades ${ }^{80}$, se constata asimismo como mecanismo habilitante para configurar la convicción del juez el relativo a las presunciones de hecho y por consiguiente el de la inversión del peso de la prueba. Dicho ejercicio puede tener lugar en dos situaciones: sea respecto de la violación de una obligación de seguridad reconocida en sede judicial (Verkehrspflicht), sea respecto de la infracción de un estatuto de protección (Schutzgesetz) ${ }^{81}$. En esta línea, se ha retenido, por una parte, la responsabilidad del profesional aplicando la teoría de

discreción, considerando la totalidad del contenido de las audiencias y el resultado de cualquier prueba practicada, si una alegación respecto de los hechos, debe ser considerado como verdadero o falso). Traducción al inglés por RüTZEL, WEgEN \& Wilske (2005), p. 224, citado por ENGEL (2009), p. 441.

${ }^{77}$ Entscheidungen des Bundesverfassungsgerichts (BVerfGE - Federal Constitutional Court) (1979) citado por StaUch (2011), p. 1153.

78 Artículo 103 de la Constitución (Grundgesetz):"Vor Gerich thatjedermann Anspruchaufrechtliches Gehör" (Toda persona tiene derecho a un juicio justo en un Tribunal), visto en STAUCH (2011), p. 1153.

${ }^{79}$ Stauch (2011) p. 1155.

${ }^{80}$ Op. cit., p. 1154.

${ }^{81}$ Oliphant (2011), p. 1617. 
los riesgos totalmente dominables ${ }^{82}$, en circunstancias que habiéndose producido el daño, el peso de la prueba se invierte toda vez que la magnitud del riesgo al que se expuso el paciente es incompatible con el desenlace verificado (res ipsaloquitur ${ }^{33}$ ); mientras que por otro, afirmamos que la aplicación más característica es la que se refiere a casos de negligencia médica manifiesta. Respecto de esta última categoría la Corte Suprema alemana (Bundesgerichtshof) ha establecido que una negligencia médica manifiesta corresponde a aquel error que en atención a la competencia y formación objetivamente requerida de los médicos, no debe ser cometida ${ }^{84}$. Con ello se excluyen aquellos errores que pueden ser observados por aquel profesional que realiza su trabajo a conciencia. Sin perjuicio de lo anterior, ha sido retenida la responsabilidad del facultativo en eventos en los que se ha aumentado o creado en más de un mínimo el riesgo de daño, aun cuando este sea inferior al riesgo representado por causas alternativas del daño. En este sentido, el máximo tribunal retuvo la responsabilidad del médico bajo el argumento de un diagnóstico errado, aun cuando fue demostrado que el tratamiento adecuado representaba el 10\% de posibilidades de recuperación ${ }^{85}$.

3. Consideramos interesante referirnos, asimismo, a la situación de Quebec. Los tribunales de la indicada provincia canadiense, heredera de la tradición jurídica francesa, han adoptado en varias decisiones el Common Law en atención a la flexibilidad con la que la Corte Suprema de Canadá resuelve los problemas sometidos a su conocimiento (hacemos presente que el máximo tribunal resuelve según las normas del Common Law o del Civil Law, según el sistema legal bajo el cual se pronunció la apelación). Ejemplo de la flexibilidad aludida corresponde al contencioso Snell con Farrell (1990). En la causa señalada, el demandante se sometió a un procedimiento quirúrgico en el que el cirujano admitió que su tratamiento se redujo por debajo del nivel requerido de atención. El demandante sufrió un derrame cerebral desarrollando, en consecuencia, una ceguera. $\mathrm{Ni}$ demandante ni demandado estaban en condiciones de probar que la ceguera se había o no desarrollado a causa del derrame o de la negligencia cometida. Luego, la prueba pericial no pudo establecer o desvirtuar una relación de causalidad basada en una balanza de probabilidades (en Quebec se sigue un régimen de causalidad jurídica que debe ser justificada por una probabilidad superior al 50\%, que se aprecia, a su vez, mediante

${ }^{82}$ Stauch (2011), p. 1154 y Stauch (2008), pp. 74-76.

83 "Las cosas hablan por sí mismas".

${ }^{84}$ Oliphant (2011), p. 1617.

${ }^{85}$ Bundesgerichtshof (BGH-Federal Court of Justice) (2004), citada por OliPHANT (2011), p. 1618. 
el análisis de todos los elementos de evidencia científica incorporados en el proceso). Es por lo anterior que el único camino conducente a la retención de la responsabilidad del agente correspondió a la inferencia jurídica flexible de la causalidad, lo cual se verificó en la especie.

Siguiendo a la profesora Lara Khoury ${ }^{86}$ constatamos como el recurso a presunciones de hecho también ha sido una directriz en Quebec a título de mecanismo para salvar la incertidumbre científica. El núcleo justificante del razonamiento ha correspondido al riesgo en la que se ve envuelta la acción imputable al agente respecto de contenciosos de negligencia médica. La jurisprudencia en este sentido se alinea según lo resuelto en Lafèrriere con Lawson (1991) en la que se retuvo la responsabilidad de un médico en atención a la culpa por este cometida, puesto que representa un peligro para el paciente. Luego, si el peligro se materializa "puede ser razonable para el juez presumir la relación de causalidad entre la culpa y el daño"87. Con inspiración en este criterio, años más tarde, en el juicio Prat con Poulin (1997) la Corte de Apelaciones de Quebec pronunció una sentencia condenatoria basándose en la omisión de la información por parte del facultativo respecto de suspender la ingesta de píldoras anticonceptivas con anterioridad a una operación por el riesgo de sufrir una trombosis. En los hechos, se concretizó el riesgo y la trombosis tuvo lugar. Se hizo 238 presente que el accidente vascular podría haberse verificado igualmente sin una intervención quirúrgica de por medio, sin embargo, dicho argumento fue desestimado. Asimismo, en Chouinard con Robbins (2001), la misma Corte de Apelaciones, resolvió que el retraso en el tratamiento de una enfermedad podría ocasionar un daño cerebral. En la especie, el retraso se comprobó, el daño se produjo y la responsabilidad del médico retenida, aun cuando científicamente es probable que la lesión cerebral pudiera haberse producido recibiendo el enfermo una atención oportuna. Sin perjuicio de lo anterior, la Corte Suprema de Canadá en el contencioso St-Jean con Mercier (1999) se opuso a la condena de un médico basada en la consideración exclusiva del riesgo como mecanismo habilitante para formar convicción mediante vía de presunción judicial. En efecto, fue considerado el ejercicio como un mecanismo dirigido a eludir las reglas tradicionales de la prueba y del balance de probabilidades. Es así como el máximo tribunal canadiense determinó que las presunciones judiciales deben fundarse en hechos individuales apreciables en cada caso.

4. Por último,el Derecho estadounidense se ha pronunciado también sobre esta contingencia en el ya referido Restatement (third) of torts liability

\footnotetext{
${ }^{86}$ KHOURY (2007), pp. 143-144.

${ }^{87}$ Lafèrriere con Lawson (1991), pp. 542-543: “...itmaybe reasonablefor a judgeto presume the causal link betweenthefault and suchdamage...”.
} 
for physical and emotional harm (2010) en su Sección 28 c, disposición que es vinculada con la problemática de los toxic torts, de la manera siguiente:

"El demandante debe demostrar en virtud de una evidencia preponderante que, sin la conducta ilícita del demandado con respecto a la sustancia tóxica, no habría sufrido el daño. Cuando la evidencia estadística es ofrecida en un caso, ésta debe significar que la sustancia debe ser capaz de causar la enfermedad ('causalidad en general') y que la sustancia debe haber causado la enfermedad del demandante ('causalidad específica'). En otros casos, cuando la evidencia no es disponible o no es concluyente, y otros medios de prueba son utilizados, la causalidad general y específica puede ser fusionada en una sola investigación. En cualquier caso, la exposición del demandante al agente tóxico debe ser establecida" ${ }^{88}$.

Apreciamos como el Derecho desprendido de la citada recopilación normativa y jurisprudencial se refiere a que la convicción del juez debe ser configurada con base en la regla de la probabilidad evidente o de la preponderance of theevidence (también denominada more likelythannot). De la regla enunciada se entiende, que lo que en definitiva debe ser establecido por la víctima, es que el agente en cuestión, ha intervenido de manera más determinante en el daño que los otros factores involucrados en el proceso causal, también denominados factores inocentes, o dicho en otras palabras, que la probabilidad que el demandado haya causado el daño es más alta que la probabilidad que no. Así, si uno de estos factores inocentes representa una mayor o igual probabilidad de estar a la cabeza del daño, la acción en responsabilidad no podrá prosperar. Luego, si con posterioridad a la aplicación de una vacuna, el paciente presenta una infección y muere, para poder retener la responsabilidad por el producto defectuoso (estimando que fue la vacuna quien causó la muerte) habrá que demostrar que este representa más probabilidades respecto del cuadro infeccioso sufrido de configurar la explicación del desenlace ${ }^{89}$.

88 "The plaintiff must prove by a preponderance of the evidence that, but for the defendant's tortious conduct with respect to the toxic substance, the plaintiff would not have suffered harm. When group-based statistical evidence is proffered in a case, this means that the substance must be capable of causing the disease ("general causation") and that the substance must have caused the plaintiff's disease ("specific causation"). In other cases when group-based evidence is unavailable or inconclusive, and other forms of evidence are used, the general and specific causation issues may merge into a single inquiry. In any case, plaintiff's exposure to the toxic agent must be established".

${ }^{89}$ Así lo ilustra el § 26 (4-5) del Restatement (third) of torts liability for physical and emotional harm (2010). 
La disposición transcrita adopta, asimismo, una de las reflexiones observadas en el contencioso denominado "agente naranja", como pasaremos a exponer brevemente. El "agente naranja" constituyó una de las armas químicas utilizadas por Estados Unidos en la guerra de Vietnam. A fines de la década de 1970 un conjunto de veteranos del ejército estadounidense, apoyados por informes científicos, expusieron a los tribunales la posibilidad cierta de haber transmitido malformaciones congénitas a sus hijos, a causa de haber estado en contacto con el producto en cuestión. La incertidumbre provocó una serie de demandas en contra del fabricante del defoliante, las cuales se resolvieron mediante el acuerdo entre las víctimas y el industrial. La solución ideada por el juez Jack Weinstein ${ }^{90}$ se debió a que, si bien era posible atribuir una causalidad general entre el daño y la acción del químico, dicha causalidad no podía extrapolarse al nexo específico que requería justificar el dañado siguiendo la regla tradicional del "more like lythannot". En definitiva, las demandas fueron colectivizadas y los juicios radicados en un tribunal de Nueva York. La técnica de Jack Weinstein estuvo dirigida a agrupar las demandas en una acción de clase y estimar estadísticamente el daño que el producto produjo, distribuyéndolo entre los afectados. La originalidad del citado juez, fundada en gran medida en los estudios de David Rosenberg quien ha defendido que el recurso a 240 las acciones de clase en litigios relativos a daños en masa, considerando, por ejemplo, que el recurso a ellas debía ser obligatorio ${ }^{91}$. El recurso a las acciones de clase en Estados Unidos no se ha visto exento de secuelas. En efecto, en el año 2010 noventa y seis compañías de las industrias del asbesto acabaron incursas en situación concursal ${ }^{92}$, lo cual no es otra consecuencia que la verificación de una intensa crisis de litigación. De aquí que en la actualidad los tribunales adopten estrictos cánones de viabilidad de este tipo de acciones ${ }^{93}$.

Pues bien, volviendo a la sección 28 c del Tercer Restatement, podemos afirmar que la disposición enunciada constituye un pronunciamiento expreso respecto del problema de la incertidumbre científica, el cual, si bien constituye un aporte, debe ser considerado con cautela ${ }^{94}$. Por su parte, el pronunciamiento verificado en el Restatement señalado, en nuestro juicio, pretende hacerse cargo de un vacío que hasta la época existía en el sistema americano en el capítulo relativo a los toxic torts, el cual no atacado puntualmente por el Segundo Restatement (1965), vino

\footnotetext{
${ }^{90}$ KLeIN (2008), p. 18.

${ }^{91}$ Rosenberg (1984), p. 849, citado por Klein (2008), p. 19.

${ }^{92}$ Azagra (2011), p. 54.

${ }^{93}$ Op. cit. (2011), pp. 48, 167 y ss.

${ }^{94}$ Hudson (2010), p. 10.
} 
a integrar los anales de jurisprudencia a partir del contencioso Borel v. Fiber board Paper Prods. Corp (1973). Hacemos presente que el juicio apuntado constituyó el primer litigio que en materia de asbesto fue resuelto a favor de la víctima. Su particularidad corresponde a que la órbita de responsabilidad no se reduce solo a los empleadores sino que también a los proveedores e instaladores del material. Reiteramos en este punto las observaciones que han sido formuladas respecto de la sección en referencia ${ }^{95}$, en cuanto a la distinción de causa general y específica, toda vez que consideramos que la retención de una estricta dualidad en el vínculo obedece a una errónea apreciación. Como señala el profesor Joseph Sanders, cada caso de responsabilidad tóxica es único y, si bien la causalidad puede ser demostrada por ambas vías, en ciertas situaciones el nexo puede ser determinado con base en las pruebas presentadas bajo una perspectiva genera $^{6}$. Es así como lo señala la parte final de la norma en referencia al establecer "la causalidad general y específica puede ser fusionada en una sola investigación" ${ }^{97}$. Así las cosas, inferencias razonables fundadas en la experiencia y en conexiones temporales y espaciales las estimamos como suficientes para constatar el vínculo entre hecho generador y daño. Apreciamos la similitud en el razonamiento expuesto respecto del criterio esbozado por tribunales franceses en el contencioso de las vacunas contra la hepatitis $\mathrm{C}$ y su vinculación con la esclerosis en placas, visto más atrás ${ }^{98}$. Naturalmente lo anterior no obsta a que sea conveniente al legar todos los antecedentes de que se disponga para justificar la petición de resarcimiento. De aquí que si de causas conocidas solo puede explicarse una parte del mal sufrido bien pueden ser requeridas pruebas independientes respecto de la toxicidad de un fármaco, por ejemplo.

4.1. Prueba pericial en Estado Unidos y sus consecuencias en la inferencia de la causalidad

Incompleto resultaría este trabajo, si en este punto no nos pronunciáramos respecto de las consecuencias que la sentencia dictaminada en Daubert con Merrell Dow Pharmaceuticals, Inc. (1993) ha promovido en el escenario estadounidense, respecto del papel de la prueba pericial en la inferencia de la causalidad. Sobre lo indicado el Restatement antes señalado no se pronuncia, esto se expone de manera expresa en las notas al comentario c de la sección 28:

\footnotetext{
${ }^{95}$ Sobre este punto, véase supra p. 4.

${ }^{96}$ SANDERs (2009), p. 5.

97 "...the general and specific causation is sues may merge into a single inquiry".

${ }^{98}$ Sobre este punto, véanse pp. 19-20.
} 
"Este comentario no se refiere ni intenta resolver el estándar apropiado para determinar la admisibilidad de la prueba pericial sobre la causalidad entre el agente y el daño" ${ }^{99}$.

Pues bien, en Daubert con Merrell Dow Pharmaceuticals, Inc.fueron resueltos dos casos de malformaciones congénitas sufridas por los hijos de dos mujeres a las que se les recetó el medicamento Bendectin con el propósito de evitar nauseas matinales durante sus respectivos embarazos. Los demandantes sostuvieron que el daño derivaba de la ingesta del medicamento. En primera instancia, el Tribunal de Distrito rechazó la demanda de los afectados. Fueron retenidas positivamente las pruebas científicas presentadas por el industrial relativas a que en más de ciento treinta mil pacientes tratados con el mismo fármaco ninguno de ellos había presentado problemas similares. A su turno, los demandantes hicieron valer pruebas materializadas en ejercicios científicos en tubos de ensayo, con animales y farmacológicos respecto de otros productos de similar composición cuya nocividad era conocida. El indicado tribunal dictaminó que la responsabilidad del demandado no podía verse comprometida, pues la causalidad no había sido probada. En este sentido, fueron desestimadas las pruebas presentadas por los demandantes estableciéndose que de ellas no era po242 sible establecer un vínculo entre el producto y el daño respecto de seres humanos. Además, los informes científicos presentados por los demandantes no revestían el mérito de configurar medio de prueba pertinente, pues no habían sido publicados por sus autores, ni sometidos a la revisión de sus pares. En segunda instancia, el criterio pronunciado por el tribunal fue similar; se centró fundamentalmente en el escaso mérito científico de las pruebas presentadas por los actores. Respecto de los informes periciales presentados, fueron considerados insuficientes en atención a su carácter de inédito y de su preparación exclusiva para el juicio, además de no haber sido sometido a la revisión de la comunidad científica ${ }^{100}$. La Corte Suprema, por su parte, sentó las bases modernas de la prueba pericial en Estados Unidos, al establecer que es de competencia de los jueces de primera instancia determinar si el experto prestará testimonio en juicio. La indicada autorización deberá fundarse en cuatro factores no excluyentes, a saber:

a) Testability: la formulación científica debe ser expresada en hipótesis y ser contrastadas;

b) Peer review and publication: la teoría o la técnica expuesta en el informe científico debe ser publicada y ser sometida a la revisión

99 "This Comment does not address norattempt to resolve the appropriate standard for determining the admissibility of expert testimony on agent-disease causation"

${ }^{100}$ Salvador y Rubí (2008), pp. 32-33. 
de la comunidad científica, aunque no obligatoriamente. De aquí que la publicación del trabajo sea representativo de un signo de "buena ciencia"101;

c) Potential rate of error and standards controll ing the scientific technique's operation: lo cual se refiere a la consideración por parte del tribunal de la tasa de error conocida o, bien, potencial de la técnica o teoría científica, así como la fiabilidad de la técnica científica utilizada;

d) Generally accepts the theory or technique: aceptación generalizada por parte de la comunidad científica de la teoría o de la técnica en cuestión ${ }^{102}$.

A su turno, los criterios expuestos en Daubert fueron consolidados con posterioridad en dos juicios en los que la Corte Suprema, además de recordar que el rol que asiste a los tribunales de primera instancia en orden a ser los fiscalizadores de la aptitud jurídica del informe pericial, estableció que los criterios debían leerse extensivamente, es decir, respecto de toda clase de expertos.

La primera de estas sentencias fue pronunciada en el contencioso General Electric Co. con Joiner (1997). En este caso, un enfermo de cáncer pulmonar alegaba que su enfermedad había sido originada a causa del contacto con PCB. Sin perjuicio de lo anterior, el enfermo era fumador y presentaba un historial familiar de eventos cancerígenos a causa del cigarrillo. El tribunal de primera instancia rechazó la demanda en aplicación de los postulados en Daubert, estimando que los cuatro estudios epidemiológicos presentados no permitían atribuir causalidad entre la enfermedad y la fuente del daño. En segunda instancia se revocó el pronunciamiento del tribunal inferior, en atención a las Reglas Federales de Evidencia $^{103}$, considerándose la admisibilidad del testimonio del experto. La Corte Suprema, a su turno, rechazó la apelación, confirmó que las fundamentaciones del demandante se basaban en la mera especulación, considerando que bien el tribunal de primera instancia puede justificar su sentencia en que "simplemente resulta demasiado amplia la brecha analítica entre los datos y la opinión propuesta" ${ }^{104}$ así como que

${ }^{101}$ Salvador y Rubí (2008), pp. 23-27 y 30-39.

${ }^{102}$ Para revisar las condiciones, Daubert v. Merrell Dow Pharmaceuticals, Inc. (1993), pp. 592-594.

${ }^{103}$ Las Federal Rules of Evidence tienen por objetivo uniformar las disposiciones relativas a la prueba en juicio. Si bien su observancia no es obligatoria, su valor de convicción es alto entre los distintos estados.

104 "... that there is simply too great an analytical gap between the data and the opinion proffered" (cons. III). 


\begin{abstract}
“nada, ni en Daubert ni en las Reglas Federales de Evidencia, exige que el Tribunal de Distrito admita una opinión a título de prueba en virtud de la sola declaración del experto" ${ }^{105}$.
\end{abstract}

Por último, se hace referencia a la facultad que reside en los tribunales de primera instancia en orden a ejecutar la obligación de ser fiscalizadores de la validezjurídica del testimonio del experto, también denominado gatekeeping ${ }^{106}$.

La segunda sentencia resolvió el litigio Kumho Tire con Carmichael (1999). El mérito de este contencioso obedece a la extensión de la regla Daubert a eventos en que no puedan calificados como científicos sino que como técnicos. En los hechos, producido el reventón del neumático de un vehículo se demandó la responsabilidad del fabricante del neumático, presentándose como prueba la declaración del experto. El Tribunal de Distrito, a la luz de los criterios Daubert consideró que la causalidad no podía ser inferida. La Corte de Apelaciones, revocando la decisión, estimó que los criterios Daubert solo podían ser invocados en contenciosos científicos, no técnicos. La Corte Suprema, por su parte, revocó la sentencia del Tribunal de Alzada estimando que la obligación que asume el Tribunal de Distrito en orden a ser el fiscalizador o gatekeeping de la aptitud del testimonio pericial se extiende a todo tipo de experto, debiendo estarse el 244 tribunal más bien a las circunstancias del caso ${ }^{107}$.

Cabe destacar que la trascendencia de los criterios retenidos en Daubert representa un interés amplio. Lo anterior, pues vinieron a alterar formalmente las reglas que, hasta la época, eran seguidas en materia de incertidumbre científica. El impacto se manifestó de modo categórico en dos escenarios:

Por un lado, respecto de la norma desprendida del contencioso Frye con United States (1923): en el litigio indicado, relativo a un proceso penal en el que fue discutido si la víctima podía ser sometida a un detector de mentiras, se estableció que la prueba pericial debía ser retenida según la "general acceptance" o la aceptación generalizada de la opinión científica relativa al objeto de la litis. Así, la regla de la "aceptación generalizada" que en rigor había sido seguida por el tribunal de primera instancia en Daubert, sufre una alteración radical en cuanto a su naturaleza. Pues si antes

105 "Nothing in either Daubertor the Federal Rules of Evidence requires a district court to admit opinion evidence that is connected to existing data only by the ipse dixit of the expert" (cons. III).

106 "... they leave in place the "gate keeper" role of the trial judge in screening suchevidence...” (cons. II).

107 "The conclusion, in our view, is that we cannei ther rule out, nor rule in, for all cases and for all time the applicability of the factors mentioned in Daubert, norcanwenow do so for subsets of cases categorized by category of expert or by kind of evidence. Too much depend supon the particular circumstances of the particular case at issue" (cons. II B). 
era estimada como el exclusivo elemento de la esencia de la resolución que se pronunciaba sobre la pertinencia de la declaración pericial, ahora era un elemento más a considerar, sin que su ausencia provocara forzadamente el rechazo al informe técnico o teórico del experto. En este sentido

“el juez podía denegar la práctica de la prueba pericial propuesta por una parte y, por lo tanto, impedir que el jurado oyera al perito si consideraba que los fundamentos de la prueba no habían logrado aceptación general entre los expertos del correspondiente ámbito del conocimiento" 108 ;

y, por otro, la modificación del artículo 702 del cuerpo de Reglas Federales de Evidencia. La norma establecía:

"Cuando los conocimientos científicos, técnicos u otros especializados puedan servir al Jurado para entender las pruebas o establecer los hechos del caso, podrá tenerse en cuenta el testimonio de un perito experto por razón de conocimiento, habilidad, experiencia, formación o educación en el que exprese su opinión"109,

es decir, que el experto sería oído siempre que su relato fuera importante en relación con su experiencia, habilidad o formación. Hacemos presente que la disposición enunciada ha sido alterada en dos ocasiones, ambas a consecuencia de los criterios desprendidos de Daubert. La primera modificación se verificó en el 2000, en que se dispuso:

"Podrá tenerse en cuenta el testimonio de un perito calificado como experto por razón de conocimiento, habilidad, experiencia, formación o educación en el que exprese su opinión si: (a) el testimonio está suficientemente fundado en hechos o datos fiables, (b) el testimonio es producto de principios y métodos fiables, y (c) el testigo aplica los principios y métodos a los hechos del caso de forma fiable"

${ }^{108}$ SAlvador y Rubí (2008), p. 32.

109 "If scientific, technical, or other specialized know ledge will assist the trier of fact to understand the evidence or to determine a fact in issue, a witness qualified as an expert by knowledge, skill, experience, training, or education, maytestify there to in the form of an opinion or otherwise".

110 "If scientific, technical, or other specialized know ledge will assist the trier of fact to understand the evidence or to determine a fact in issue, a witness qualified as an expert by know ledge, skill, experience, training, or education, maytestify there to in the form of an opinion or otherwise, if (a) the testimonyis sufficiently based upon reliable facts or data. (b) the testimonyis the product of reliable principles and methods, and (c) the witness has applied the principles and methods reliably to the facts of the case". 
mientras que la segunda se produjo en el 2011, como parte del rediseño de las reglas de la prueba con el exclusivo objeto de que fueran más fáciles de entender, sin pretender alterar el sentido de la norma modificada; la disposición indica:

"Podrá tenerse en cuenta el testimonio de un perito experto por
razón de conocimiento, habilidad, experiencia, formación o
educación en el que exprese su opinión si: (a) los conocimientos
científicos, técnicos u otros del experto, contribuirán al juez en la
comprensión de los hechos con el fin de entender la evidencia o
determinar el hecho en cuestión, (b) el testimonio está suficien-
temente fundado en hechos o datos fiables, (c) el testimonio es
producto de principios y métodos fiables, y (d) el experto aplica
los principios y métodos a los hechos del caso de forma fiable"111.

Sin perjuicio de lo anterior, una distinción se impone en cuanto al cuestionable aporte de la comentada trilogía. De aqui que estimemos pertinente enfocarnos en las consecuencias de las alteraciones expuestas más atrás, tanto desde una perspectiva intelectual como práctica.

Reconocemos la utilidad de la doctrina Daubert en una óptica intelec246 tual, pues permite combatir la denominada ciencia basura o junkscience. De esto que no cualquier informe científico revista el mérito suficiente para poder demostrar o inferir la vinculación de un daño a una fuente nociva. La corriente es positiva entonces, en el marco de la justificación demostrada por el experto a través de su informe, la cual debe ser expuesta fundadamente sin falsedades ni especulaciones ${ }^{112}$. En este escenario la doctrina estadounidense ha considerado como un aporte significativo la retención de los criterios Daubert ${ }^{13}$ en atención a la calidad de la prueba

111 "A witness who is qualified as an expert by know ledge, skill, experience, training, or education may testify in the form of an opinion or other wise if: (a) the expert's scientific, technical, or other specialized know ledge will help the trier of fact to understand the evidence or to determine a fact in issue; (b) the testimony is based on sufficient facts or data; (c) the testimony is the product of reliable principles and methods; and (d) the expert has reliably applied the principles and methods to the facts of the case".

${ }^{112}$ En este sentido Salvador y Rubí (2008) p. 42, exponen: “ (...) en tanto en cuanto ha llamado la atención sobre la necesidad de exigir credenciales fiables a los expertos presentados por las partes respondiendo además al desiderátum natural de cualquier ciudadano -es decir, de cualquier miembro potencial de un jurado- quien, idealmente, ansía gestionar sus asuntos o adoptar decisiones que le conciernen tras informarse por boca del mejor profesional en lugar de tener que hacerlo después de oír a cualquiera que se autoerige como tal".

${ }^{113}$ Véase, por ejemplo, Bernstein (2002), pp. 1-2; Gutheil y Bursztajn (2005), pp. 150-152; Schwartz y Silverman (2006), p. 217 y ss. 
científico-pericial. Voces como la de David Owen o de David Bernstein, se suman a este criterio. El primero manifiesta:

"con posterioridad a Daubert, los tribunales federales de distrito, en ejercicio de su función denominada 'gatekeeping', han examinado el testimonio de los expertos más de cerca, a menudo sosteniendo rigurosas selecciones 'Daubert preventivas' -que normalmente son determinantes en cuanto al resultado- para establecer la admisibilidad del testimonio propuesto por el experto" ${ }^{114}$;

el segundo, pronunciándose favorablemente respecto de la actitud adoptada por los Tribunales de Distrito, en ejercicio de su obligación de fiscalizadores del mérito probatorio del testimonio científico ofrecido como parte de prueba, en orden a la cual se han desestimado en mayor porcentaje aquellos informes que son basados en una "post hoc clinical evidence", esto es, que la víctima puede sostener que una sustancia causó la lesión simplemente porque el demandante se vio expuesto a ella con anterioridad al daño ${ }^{115}$.

Ahora bien, desde un punto de vista práctico las opiniones difieren. El cuestionamiento fundamental está centrado en la capacidad de los jueces para verificar el rigor científico de la intervención pericial y, en definitiva, en la retención de la prueba a título de "buena ciencia". Pareciera que los tribunales otorgan validez exclusiva a estudios epidemiológicos, en circunstancias que estos son altamente costosos, no quedando alternativas a los demandantes de extrapolar estudios en animales, los cuales tal como sucedió en General Electric Co. con Joiner (1997) se rechazan. En este sentido ha sido resuelto:

"La idea relativa a que es posible extrapolar con precisión datos animales respecto de humanos para probar la causalidad sin contar con un soporte en estudios epidemiológicos es científicamente inválido, pues esto es inconsistente en atención de varios principios aceptados y testeados científicamente. (...) ha sido testeado y probado que diferentes especies reaccionan de manera diferente respecto de un mismo agente" ${ }^{116}$.

${ }^{114}$ Owen (2003), p. 362. "Post-Daubert, the federal district courts, exercising their new lyap pointed 'gatekeeper' function, have scrutinized expert testimony more closely, often holding rigorous pre-trial 'Daubert hearings' -that are often out come determinative- to determine thead missibility of proffered expert testimony".

${ }^{115}$ Bernstein (1994), p. 2147, citado por Schwartz y Silverman (2006), p. 230.

${ }^{116}$ Wade-Greaux con Whitehall Laboratories (1994), No 36: "The notion that one canaccurately extra polate from animal data to human to prove causation with out supportive epidemiologic studies is scientifically invalid because it is inconsistent with 
Por nuestra parte, no pretendemos afirmar que un estudio en animales represente un mayor valor probatorio que un epidemiológico, ello escapa a nuestras competencias, sin embargo, estimamos que requerir en sede de causalidad jurídica niveles de certeza imposibles de demostrar en sede de causalidad científica constituye un equívoco. Causalidad jurídica y causalidad científica obedecen a dos nociones que difieren entre sí, y si bien pueden verse identificadas en un escenario de certeza, un supuesto de incertidumbre técnica no puede constituir de forma refleja argumento válido para rechazar el resarcimiento de la víctima. Un claro ejemplo de esta cuestionada similitud de estándares corresponde al observado en varias jurisdicciones estadounidenses a propósito de las supuestas consecuencias del medicamento Parlodel. El fármaco en cuestión fue recetado a aquellas madres que deseaban suprimir el amamantamiento de sus hijos. Frente a eventos de accidentes cardiovasculares el stock del producto fue interrumpido. Con posterioridad, fueron presentadas acciones civiles solicitando retener la responsabilidad del fabricante. Respecto de la prueba de la causalidad, diversos Tribunales de Distrito reconocieron la aptitud del experto para ser oído en juicio, mientras que otros rechazaron la prueba científico-pericial. En los informes científicos fueron consideradas pruebas en animales, dictámenes médicos y un cuadro del estado de salud de las mujeres una vez que suspendieron 248 la droga. No obstante lo expuesto, las pruebas epidemiológicas fueron débiles, en relación con que no configuraron un resultado concluyente. Lo anterior, constituyó fundamento suficiente para sostener, por algunos tribunales, que la prueba no era suficiente, llegándose a estimar que "con respecto a la causalidad general, el campo científico relevante es la epidemiología o la toxicología y no la medicina clínica"17.

Cabe mencionar aquí, los argumentos que expone Carl Cranor para sostener que la jurisprudencia Daubert es negativa respecto de aquella víctima que no puede acceder a una prueba científica irrefutable como argumento de causalidad. Tres son los motivos principales:

a) que el estudio de las sustancias tóxicas conlleva limitaciones estructurales (producen resultados inciertos);

b) que las nuevas reglas de evaluación del conocimiento científico derivadas de la trilogía Daubert, que se aplican en los juicios sobre sustancias tóxicas, han impuesto un incremento del peso de las pruebas contra los demandantes y

several universally accepted and tested scientific principles. (...) has been tested and demonstrates that different species canreact differently to the same agent".

${ }^{117}$ Siharath con Sandoz Pharmaceuticals Corp. (2001), sección C. Case Reports: "with regard to general causation, the relevant scientific fieldis epidemiology or toxicology and not clinical medicine". 
c) que las agencias gubernamentales tienen limitaciones para regular (previa detección científica de su toxicidad) todas las sustancias que entran en el mercado, ya que su estudio es lento y costoso ${ }^{118}$. Concentrándonos en los dos primeros argumentos, Carl Cranor los vincula respecto del papel del juez que se enfrenta a la problemática de la incertidumbre científica. En este sentido el indicado autor manifiesta que en muchas de sus decisiones los jueces cometen importantes errores científicos ${ }^{119}$. Carl Cranor argumenta que los jueces han sobrevalorado ciertos tipos de estudios científicos, mientras que han minusvalorado otros. Esto se debe a que los jueces no están familiarizados con los patrones de razonamiento que realizan los científicos para determinar la causalidad de una determinada sustancia o proceso. A ello se añade el hecho de que algunas de las características estructurales de las sustancias tóxicas hacen que su estudio sea más difícil ${ }^{120}$.

Resulta evidente, en nuestro criterio, que el papel del juez es fundamental en el tema que comentamos. Sin perjuicio de lo anterior, el ente jurisdiccional podrá desarrollar su cometido de la mejor forma posible solo si sus competencias alcanzan dominio pluridisciplinar. Luego, existen más posibilidades que el tribunal eleve los estándares de la causalidad jurídica en el evento que el juez carezca de competencias suficientes para analizar debidamente la vinculación científica entre agente y daño. En esta labor, una correcta comunión con el experto otorgará, estimamos, mayores garantías a la víctima de obtener el resarcimiento esperado. Dicha vinculación no se traduce en la demostración al 100\% que el agente ha producido un daño, escasa utilidad representaría esta comunicación. Pues en un universo de incertidumbre científica el experto sabe muy poco sobre el surgimiento de males y de sus causas de modo certero (lo que el profesor Troyen A. Brennan califica, bajo un sentido mecanicista). La gran utilidad del científico, luego, no radica en la certeza sino en la probabilidad y el indicio; en asociaciones estadísticas y medios indirectos de inferencia ${ }^{121}$.

Avanzando un poco más en el análisis, sostenemos que el aislamiento y el exagerado apego a fórmulas clásicas no son capaces de contener los avatares del siglo XXI en materia de daños ligados a la ciencia y la tecnología. Nuestro país no se encuentra al margen de esta problemática. En este sentido, elocuentes son las palabras de la profesora nacional Andrea Vivanco M. quien enseña:

\footnotetext{
${ }^{118}$ CRANOR (2006), reseñado por GiL (2008), p. 194.

${ }^{119}$ Ibid.

${ }^{120}$ Op. cit., p. 195.

${ }^{121}$ En este sentido, Brennan (1989), pp. 20-25, citado por Poulter (1992), pp. 209-210.
} 
"esta desconexión entre las ciencias (...) ha redundado en que existan en nuestro país temas no resueltos jurídicamente o que terminan siendo normados bajo supuestos inexistentes o incompletos; resolución de casos por nuestras cortes sin los debidos insumos; desinterés de nuestros legisladores respecto de procesos que concitan atención mundial, y una falta de colaboración en materias en que no sólo se verían con buenos aportes de todos, sino que se requieren para contar con soluciones de calidad" 122 .

Luego, el Derecho, en cuanto ciencia, requiere de otras ramas del saber, tanto respecto de su gestación como de su aplicación a un caso concreto. No debiendo verse limitado frente a la falta de prueba científica enmarcada en un esquema de causa a efecto al 100\%.

Por último, estimamos como manifestación del aislamiento al cual hemos hecho referencia, la función de fiscalizadores o gatekeeping de la prueba científico-pericial, que las referidas sentencias que componen la trilogía Daubert asignaron a los Tribunales de Distrito. Constatamos este papel, guardando las proporciones sistémicas, también en la jurisprudencia francesa relativa al contencioso de vacunas. En efecto, la Corte de Casación se ha pronunciado respecto del poder apreciativo de los jueces de fondo, 250 manifestando un respeto irrestricto a lo estimado por ellos, ganándose el cuestionamiento abierto de parte de la doctrina, que considera a este razonamiento propio de una actitud de Poncio Pilatos respecto de las víctimas ${ }^{123}$. El proceder del máximo tribunal francés puede ser apreciado en un caso de jurisprudencia. Una mujer recibió entre enero de 1994 y junio de 1995, tres inyecciones contra la hepatitis B. A los días de la última inyección se registraron síntomas de una esclerosis en placas. Las pretensiones de la enferma fueron rechazadas por la Corte de Apelaciones de París ${ }^{124}$. El rechazo se fundó en razón de ausencia de prueba formal de causalidad entre la vacuna y la enfermedad, no obstante la existencia de elementos que permitían retener una presunción judicial. Respecto de recurso la Corte de Casación, declaró:

“(...) la Corte de Apelaciones estimó soberanamente (...) la circunstancia que la señora $\mathrm{X}$ no presentara ningún antecedente familiar o personal y el hecho que los primeros síntomas de la enfermedad hubieran aparecido quince días después de la última vacuna, no constituyen presunciones graves, precisas y concordantes, de suerte

${ }^{122}$ Vivanco (2011), pp. 7-8.

${ }^{123}$ RADÉ (2011) p. 112.

${ }^{124}$ Goudelin con CPAM de la Seine-Saint-Denis y otros (2009). 
que no se establece una correlación entre la enfermedad de la Sra. X y la vacuna"125.

Lamentamos el panorama al que se exponen quienes padecen un mal que no pueden vincular desde un punto de vista científico a su origen. En definitiva, los enfermos se ven presos de una prueba epidemiológica técnicamente imposible, incapaz de ser integrada mediante un recurso a las evidencias del caso, quedando al arbitrio del tribunal de turno y de su valoración de la "buena ciencia".

\section{CONCLusión}

Como se desprende de la cita con la que encabezamos nuestro trabajo, la justicia es el motor con el que los ordenamientos jurídicos deben adecuar sus parámetros técnicos a esta nueva era. Parámetros susceptibles de ser modificados si una decisión o criterio parece ir en contra de lo sancionado en otras latitudes. La ciencia y la tecnología avanzan día a día. Focos potencialmente generadores de eventos de causalidad alternativa o problemas de indeterminación jurídica de la víctima, constituyen piezas infaltables del escenario en el que el Derecho de la Responsabilidad está llamado a actuar. Hemos visto como la interrogante de la proporcionalidad comienza a ser planteada en el Derecho Comparado, y aun cuando defendamos un mecanismo de solidaridad corregida, no nos debe sorprender que el debate sea abierto y sus capítulos enriquecedores. Desprendemos de lo expuesto, el papel fundamental que ocupa la víctima en los lineamientos que el instituto resarcitorio debe observar. La víctima no debe asumir la carga del perjuicio cuando este deriva del actuar científicamente riesgoso de un tercero. Para cumplir con este objetivo la contingencia de la incertidumbre científica debe ser superada, la retención de una causalidad jurídica debe imponerse. Una evidencia científica amplia, no necesariamente fundada en estudio epidemiológico, puede servir de base para el establecimiento de la causalidad. ¿No es acaso una presunción un mecanismo a través del cual a partir de un hecho conocido se infiere otro desconocido o incierto? Pues

${ }^{125}$ Goudelin con CPAM de la Seine-Saint-Denis y otros (2010). Corte de Casación. $1^{\text {a }}$ sala en lo civil. Publicada en Boletín N 1060, 09-16.556. JurisData: 2010-021936. “(...) la cour d'appel a estimé souverainement qu'en l'absence de consensus scientifique en faveur d'un lien de causalité entre la vaccination et les affections démyélinisantes, le fait que Mme X... ne présentait aucun antécédent personnel ou familial et le fait que les premiers symptômes étaient apparus quinze jours après la dernière injection ne constituaient pas des présomptions graves, précises et concordantes en sorte que n'était pas établie une corrélation entre l'affection de Mme X... et la vaccination". 
bien, si la causalidad es incierta, la presunción bien puede ser entendida como el camino para justificar el resarcimiento al cual la víctima aspira. La mera fatalidad ya no es fundamento para negar la reparación. Es en estos supuestos donde el juez debe aplicar el Derecho y hacer justicia. Para ello, debe por un lado, estar abierto a dialogar con las ciencias, bajo una imagen de observación y sin temores a la incertidumbre. La seguridad no puede ser el único espacio en el que el juez pueda hacer efectivo su ministerio. Dejamos claro, eso sí, que lo indicado no debe servir de base a una producción de culpables. La causalidad debe existir y ser justificada sin que esto signifique la generación de una nueva víctima. La formación del juez resulta entonces fundamental y su papel determinante; su vocación implica una labor activa, y no una que se agota mediante una certificación refleja de la incertidumbre científica en términos estrictos.

\section{Bibliografía CITADA}

Aberkane, Hassen (1958). "Du dommage causé par une personne indéterminée dans un groupe déterminé de personnes". RevueTrimestrielle de Droit Civil. $\mathrm{N}^{\mathrm{O}} 56$. Paris.

252 Azagra Malo, Albert (2011). "Daños del amianto: litigación, aseguramiento de riesgos y fondos de compensación”. Fundación Mapfre. Disponible en www.mapfre.com/documentacion/publico/i18n/catalogo_imagenes/grupo. cmd?path=1065299. [Fecha de consulta: 27 de agosto de 2014].

Azagra Malo, Albert (2007). "Regreso a la solidaridad". Indret-Revista para el análisis del Derecho. $\mathrm{N}^{\circ} 1$. Disponible en http://dialnet.unirioja.es/servlet/ articulo?codigo=2236419. [Fecha de consulta: 13 de agosto de 2014].

BARRía Díaz, Rodrigo (2011). "El daño causado por el miembro indeterminado de un grupo y su posible recepción en el Derecho civil chileno". Revista de Derecho Escuela de Postgrado Universidad de Chile. $\mathrm{N}^{\circ} 1$. Disponible en www. revistas.uchile.cl/index.php/RDEP/article/viewFile/22788/24174. [Fecha de consulta: 12 de agosto de 2014].

Bernstein, David (2002). "Disinterested in Daubert: State Courts LagBehind In Opposing 'Junk' Science”. Legal Opinion Letter of the Washington Legal Foundation. Disponible en www.wlf.org/upload/6-21-02Bernstein.pdf. [Fecha de consulta: 28 de agosto de 2014].

Bernstein, David (1994). "The Admissibility of Scientific Evidence after Daubert v. Merrell Dow Pharmacueticals". Cardozo Law Review. Vol. 15. No 6-7, New York.

Berros, Valeria (2013). Entramado precautorio Un aporte desde el derecho para la gestión de riesgos ambientales y relativos a la salud humana en Argentina. Tesis de doctorado. Santa Fe, Argentina: Universidad del Litoral. Facultad de Ciencias Jurídicas y Sociales. 
Brennan, Troyen (1989). "Helping Courts with Toxic Torts: Some Proposals Regarding Alternative Methods for Presenting and Assessing Scientific Evidence in Common Law Courts", en Susan Poulter (1992). "Science and Toxic Torts: Is There a Rational Solution to the Problem of Causation". Berkeley Technology Law Journal. Vol. 7. Disponible en http://scholarship.law.berkeley. edu/cgi/viewcontent.cgi?article $=1103 \&$ context $=$ btlj. [Fecha de consulta: 28 de agosto de 2014].

Boutonnet, Mathilde (2002). "L'incertitude des connaissances scientifiques appréhendée par le droit de la responsabilité civile". Disponible en http://osmose.acs.free.fr/NV/actes2002.htm. [Fecha de consulta: 20 de julio de 2014].

Corral Talciani, Hernán (2009). Responsabilidad por productos defectuosos. Análisis y propuestas para el Derecho Civily de Consumo en Chile. Santiago: LegalPublishing.

Cour de CAssation, (2008). Ordre des avocats au Conseil d'État et à la Cour de cassation, (IHEJ) Institut des Hautes Études pour la Justice, (EN3S) École Nationale Supérieure de Sécurité Sociale, (CHEA) Centre des Hautes Études de l'Assurance. "Le traitement juridique de l'incertitude". Paris: Dalloz.

Dobbs, Dan y Paul T. Hayden (1997). Torts and Compensation. Personalaccountability and social responsibility for injury. $3^{\mathrm{a}} \mathrm{ed}$. St Paul, Minnesota: West Publishing Company.

Engel, Christoph (2009). "Preponderance of the evidence versus intime conviction: a behavioral perspective on a conflict between american and continental european law”. Vermont Law Review. Vol 33. Disponible en http://papers. ssrn.com/sol3/papers.cfm?abstract_id=1401442. [Fecha de consulta: 25 de agosto de 2014].

Epstein, Richard A. (1985). "Causation and Financial Compensation: TwoFallacies in the Law of Joint Torts". Georgia Law Journal. vol. ???. Disponible en http:// chicagounbound.uchicago.edu/cgi/viewcontent.cgi?article $=2267 \&$ context $=$ journal_articles. [Fecha de consulta: 16 de agosto de 2014].

Ferey, Samuel (2013). "Pour une prise en compte des parts de marché dans la détermination de la contribution à la dette de réparation”. RecueilDalloz Paris: Dalloz.

GeistFeld, Mark A. (2006). "The doctrinal unity of alternative liability and market-shareliability". University of Pennsylvannia Law Review. Vol. 155. Philadelphia. Disponible en http://papers.ssrn.com/sol3/papers.cfm?abstract_ id $=948429 \# \#$. [Fecha de consulta: 15 de agosto de 2014].

Gil, Nofre. (2008). Reseña de Toxic Torts. Science, Law, and the Possibility ofJustice de Carl Cranor. Revista Iberoamericana de Ciencia, Tecnología y Sociedad-CTS. Vol. 4. $\mathrm{N}^{\mathrm{O}}$ 11. Disponible en www.redalyc.org/articulo.oa?id=92441113. [Fecha de consulta: 29 de agosto de 2014].

Gutheil, Thomas G. y Harold Bursztajn (2005). "Attorney Abuses of DaubertHearings: Junk Science, Junk Law, Or Just Plain Obstruction”. J Am Acad Psychiatry Law. $\mathrm{N}^{\circ}$ 33. Disponible en www.jaapl.org/content/33/2/150.full. [Fecha de consulta: 28 de agosto de 2014]. 
Hudson, Eric E. (2010). "Comment C on Toxic Torts in the RestatementThird". ABA Section of Litigation, Mass Torts Newesletter. Disponible en www.butlersnow. com/eric_hudson.aspx. [Fecha de consulta: 10 de agosto de 2014].

Jourdain, Patrick (2001). "Causalité juridique et incertitude scientifique. A propos du lien de causalité entre le vaccin contre l'hépatite B et l'apparition de la sclérose en plaques". Revue Trimestrielle de Droit Civil. No ??. Paris.

Khoury, Lara (2007). "Causation and Health in Medical, Environmental and Product Liability". Windsor Yearbook of Access to Justice. Vol. 25. N 1 . Ontario.

KLEIN, Andrew (2008). "Causation and Uncertainty: Making Connections in a Time of Change". Indiana University School of Law. Vol. ??. Disponible en http://papers.ssrn.com/sol3/papers.cfm?abstract_id=1201342. [Fecha de consulta: 26 de agosto de 2014].

LARA Khoury (2006). Uncertain Causation in Medical Liability. Oxford: Hart Publishing.

Martín Casals, Miquel (2005). "Una primera aproximación a los Principios de Derecho Europeo de la Responsabilidad Civil". Indret-Revista para el análisis del Derecho. No 2. Disponible en www.indret.com/pdf/284_es.pdf. [Fecha de consulta: 22 de agosto de 2014].

Munita Marambio, Renzo (2014). "Consideraciones sobre el efecto social de la innovación científica y algunas de sus consecuencias en la responsabilidad

254 civil”. Actualidad Jurídica. $\mathrm{N}^{\circ}$ 29. Santiago. Enero.

Munita Marambio, Renzo (2013). "La pérdida de una chance. Notas desde una perspectiva comparada". Actualidad Jurídica. $\mathrm{N}^{\circ} 28$. Santiago. Julio.

NAGAREDA, Richard (2007). Mass torts in a world of settlement. Chicago: University of Chicago Press.

Nick, Andrew B. (2008-2009). "MarketShareLiability\& Punitive Damages: The Case for Evolution in Tort Law". Colum.J.L. \& Soc. Probs. Vol. 42. Disponible en www.columbia.edu/cu/jlsp/pdf/Winter2008/02Nick42.2(revised).pdf. [Fecha de consulta: 18 de agosto de 2014].

Oliphant, Ken (2010). "Proportional Liability”, en Bea Verschraegen (coord.). Interdisciplinary Studies of Comparative and Private International Law. Vienna: Jan Sramek Verlag. Vol. 1.

OLIPHANT, Ken (2011). "Uncertainfactual causation in the thirdrestatement: some comparative notes". William Mitchell Law Review. Vol. ??. Disponible en http:// web.wmitchell.edu/law-review/wpcontent/uploads/Volume37/documents/ Oliphant.pdf. [Fecha de consulta: 20 de agosto de 2014].

Prosser, William (1971). Law of Torts. $4^{\mathrm{a}}$ ed. St. Paul, Minnesota: West Publishing Company.

QuÉzel-Ambrunaz, Christophe (2010). "La fiction de la causalité alternative, fondement et perspectives de la jurisprudence Distilbène». RecueilDalloz. Disponible en http://actu.dalloz-etudiant.fr/fileadmin/actualites/pdfs/ D2010_1162.pdf . [Fecha de consulta 14 de agosto de 2014]. 
RADÉ, Christophe (2012). “Causalité juridique et causalité scientifique: de la distinction à la dialectique. Revue Trimestrielle de Droit Civil. Vol. 19. Paris.

RADÉ, Christophe (2008). "Les présomptions d'imputabilité dans le droit de la responsabilité civile”, en Philippe Le Tourneau. Mélanges en l'honneur de Ph. le Tourneau. Paris: Dalloz.

RADÉ, Christophe (2008). "Vaccination anti hépatite B et sclérose en plaques: le tournant?". RCA. $\mathrm{N}^{\circ} 7$, étude 8. Paris. Juillet.

Ríos Erazo, Ignacio y Rodrigo Silva Goñi (2014). Responsabilidad por pérdida de la oportunidad. Santiago: Libromar Ltda.

Rosenberg, David (1984). "The Causal Connection in Mass Exposure Cases: A 'Public Law' Vision of the Tort”. Harvard Law Review. № 851. Cambridge,.

Rostron, Allen (2004-2005). "Beyond market share liability: a theory of proportional share liability for non fungible products". UCLA Law Review. N 52. Los Angeles.

RudA GonZÁlez, Albert (2003). "La responsabilidad por cuota de mercado a juicio". Indret-Revista para el análisis del Derecho. $\mathrm{N}^{\mathrm{O}}$ 3. Disponible en http:// dialnet.unirioja.es/servlet/articulo?codigo $=640118$. [Fecha de consulta: 15 de agosto de 2014].

Rützel, Stefan, Gerhard Wegen \& Stephan Wilske (2005). Commercial dispute resolution in Germany. Nördlingen: C.H. Beck.

Salvador Cordech, Pablo y Antoni Rubí Puig, (2008). "Riesgos del desarrollo y demarcación judicial de la buena ciencia". Latin American and Caribbean Law and Economics Association (ALACDE). Annual Papers, Berkeley Program in Law and Economics, UC Berkeley. Disponible en http://escholarship.org/ uc/item/68w2222m. [Fecha de consulta: 27 de agosto de 2014].

SANDERS, Joseph (2009). "The controversial comment C" (trabajo preparado para el Simposio sobre el Restatement (Third) of Torts, Wake Forest School of Law April 2-3, 2009). Disponible en http://tortssymposium.law.wfu.edu/papers/ sanders.pdf. [Fecha de consulta: 10 de agosto de 2014].

SAvatier, René, Jean SAvatier, Jean-Marie Auby and Henri Pequignot (1956). Traité de droit médical. Paris: Librairies Techniques.

Schwartz, Victor E. y Cary Silverman (2006). "The Draining of DaubertAnd The Recidivism Of Junk Science In Federal And State Courts". Hofstra Law Review. Vol. 35. Disponible en http://law.hofstra.edu/pdf/academics/journals/ lawreview/lrv_issues_v35n01_dd4_schwartz-silverman_final.pdf. [Fecha de consulta: 28 de agosto de 2014].

Shamps, Geneviève (1998). La mise en danger: Un concept fondateur d' un principe général de responsabilité. Paris: LGDJ.

Sheiner, Naomi (1978). "DES and a Proposed Theory of Enterprise Liability", Fordham Law Revue". Disponible en http://ir.lawnet.fordham.edu/cgi/ viewcontent.cgi? article $=2314 \&$ context $=$ flr. $[$ Fecha de consulta 18 de agosto de 2014]. 
SoвсzAK, Faro. "Proportionality in Tort Law". European Review of Private Law. Kluwer Law International. Vol. ??. Disponible en www.beeradvocaten.nl/pdf/ FS_Publication_ERPL_2010_18(6)_Proportionality_in_Tort_Law.pdf. [Fecha de consulta: 20 de agosto de 2014].

Stauch, Marc (2008). The Law of Medical Negligence in England and Germany: A Comparative Analysis. Portland: Hart Publishing.

Vivanco Martínez, Andrea (2011). "Derecho y ciencia: el reconocimiento de la interdisciplina”. Revista Chilena de Derecho. Vol. 38. $\mathrm{N}^{\circ}$ 1. Santiago. abril.

\section{Normativa citada}

Ante proyecto de reforma de Derecho de las Obligaciones y de la Prescripción (Ante Proyecto Catalá). Disponible en: www.justice.gouv.fr/art_pix/RAPPORTCATALASEPTEMBRE2005.pdf. [Fecha de consulta: 14 de agosto de 2014].

Código Civil. Francia.

Código de la Salud Pública. Francia.

Compensation Act Bill 2006. Disponible en www.legislation.gov.uk/ukpga/2006/29/pdfs/ukpga_20060029_en.pdf. [Fecha de consulta: 13 de agosto de 2014].

Federal Rules of Evidence. Disponible en www.law.cornell.edu/rules/fre\#article_i. [Fecha de consulta: 28 de agosto de 2014].

Principios Europeos de Responsabilidad Civil. Disponible en: http://civil.udg. edu/php/biblioteca/items/298/PETLSpanish.pdf. [Fecha de consulta: 22 de agosto de 2014].

Restatement of Torts, Second (1965). The American Law Institute.

Restatement of Torts, Third: Products Liability (1998). The American Law Institute.

Restatement of Torts, Third: Apportionment of Liability (2000).The American Law Institute.

Restatement of Torts, Third: Liability for Physical and Emotional Harm (2011). The American Law Institute.

\section{Jurisprudencia citada}

Barker con Corus UK Ltd. (2006): UKHL 20, 2 A.C. 572. Disponible en www. publications.parliament.uk/pa/ld200506/ldjudgmt/jd060503/barker-1.htm. [Fecha de consulta: 13 de agosto de 2014].

Beaulaton con CPAM de la Sarthe etautre (2008): Corte de Casación, $1^{\mathrm{a}}$ sala en lo civil, $\mathrm{N}^{\mathrm{o}}$ 05-20.317.

Belloti con Bouchet (2002): CA Bordeaux, $5^{\text {a }}$ sala en lo civil, 12 de noviembre de 2002, Nº 01-01608, Juris Data: 2002-196124. 
Borel v. Fibre board Paper Prod. Corp. (1973): 493 F.2d 1076 (5th Cir. 1973). Disponible en http://law.justia.com/cases/federal/appellate-courts/F2/493/ 1076/4552/. [Fecha de consulta: 27 de agosto de 2014].

Boultif y otros con Caisse Primaire d'Assurance Maladie (CPAM) des Bouchesdu-Rhône y otros (2010): Corte de Casación, $1^{\text {a }}$ Sala en lo civil, 17 de junio de 2010, publicada en Boletín, No 09/67.011, JurisData: 2010-009351.

Brown con Superior Court (1988): 44 Cal.3d 1049, 751 P.2d 470. Disponible en http://law.justia.com/cases/california/cal3d/44/1049.html. [Fecha de consulta: 17 de agosto de 2014].

Bundesgerichtshof (BGH-Federal Court of Justice) (2004): citada por citada por Oliphant (2011).

Consorts Fageolle con Société Laboratoires Glaxosmithkline y otros (2008):Corte de Casación, $1^{\text {a }}$ sala en lo civil, $\mathrm{N}^{\mathrm{o}}$ 06-14.952.

Chouinard con Robbins (2001): 27968 (QCCA). Disponible en http://jurisprudence. canada.globe24h.com/0/0/quebec/cour-d-appel/2001/12/10/chouinard crobbins-2001-27968-qc-ca.shtml. [Fecha de consulta: 25 de agosto de 2014].

Daubert v. Merrell Dow Pharmaceuticals, Inc. (1993): 509 U.S. 579. Disponible en https://supreme.justia.com/cases/federal/us/509/579/case.html. [Fecha de consulta: 27 de agosto de 2014].

Entscheidungen des Bundesverfassungsgerichts (BVerfGE - Federal Constitutional Court) julio 25, 1979, 52 BVerfGE131, citada por Stauch."Medical Malpractice and Compensation in Germany". Chicago-Kent Law Review. Vol. 86. Disponible en http://scholarship.kentlaw.iit.edu/cgi/viewcontent.cgi? article $=3814 \&$ context $=$ cklawreview. $[$ Fecha de consulta: 26 de agosto de 2014].

Ferrero y otros con société Novartissanté familiale y otros (2009): Corte de Casación, $1^{\mathrm{a}}$ sala en lo civil, 24 de septiembre de 2009, publicada en Boletín, No 08-16.305, JurisData: 2009-049537.

Fairchild con Glenhaven Funeral Servs. Ltd, (2002): UKHL 22. Disponible en www.publications.parliament.uk/pa/ld200102/ldjudgmt/jd020620/fchild-1. htm. [Fecha de consulta: 10 de agosto de 2014].

Frye v. United States (1923). 293 F. 1013 .C. Cir. Disponible en www.law.ufl. edu/_pdf/faculty/little/topic8.pdf. [Fecha de consulta 28 de agosto de 2014].

Gacem con Razonglesotros: Corte de Casación, $1^{\mathrm{a}}$ sala en lo civil, No 06-10.967.

General Electric Co. con Joiner (1997). 78 F.3d 524. Disponible en www.law.cornell. edu/supct/html/96-188.ZS.html. [Fecha de consulta: 27 de agosto de 2014].

Goudelin con Caisse Primaire d'Assurance Maladie (CPAM) de la Seine-SaintDenis y otros (2009), $\mathrm{N}^{\circ}$ 06/13.741, citada por Goudeun con Caisse Primaire d'Assurance Maladie (CPAM) de la Seine-Saint-Denis y otros (2010).

Goudelin con Caisse Primaire d'Assurance Maladie (CPAM) de la Seine-SaintDenis y otros (2010). Corte de Casación. $1^{\mathrm{a}}$ sala en lo civil. Publicada en Boletín No 1060, 09-16.556. JurisData: 2010-021936. 
Kumho Tire con Carmichael: 131 F.3d 1433, reversed. 131 F.3d 1433, reversed. Disponible en https://bulk.resource.org/courts.gov/c/US/526/526. US.137.97.1709.html.[Fecha de consulta: 27 de agosto de 2014].

Laferrière con Lawson (1991): Corte Suprema de Canadá. 78 D.L.R. (4th) 609, 1 S.C.R. 541. Disponible en http://scc-csc.lexum.com/scc-csc/scc-csc/en/ item/735/index.do. [Fecha de consulta: 25 de agosto de 2014].

Mariotti con Caisse primaire d'assurance maladie (CPAM) des Bouches-du-Rhône y otros (2008): Casación, $1^{\text {a }}$ sala en lo civil, 30 de octubre de 2008, publicada en Boletín, No 07-13.791, JurisData: 2008-045572.

Prat v. Poulin, (1997): R.J.Q. 2669 (C.A.), vista en Khoury (2007).

S.A. SmithklineBeecham con Morice (2001): CA Versailles, No 98-06839, JurisData: 2001-187652.

Sahraoui con Fonds d'Indemnisation des Transfusés et hémophiles contaminés par le VIH (FITH) (2005): Corte de Casación, $2^{\text {a }}$ sala en lo civil, No $05 / 06.005$, JurisData: 2005-031362.

SAS Laboratoire Glaxo-Smithkline con Morice Jeanpert (2003): Corte de Casación, $1^{\mathrm{a}}$ sala en lo civil, publicada en Boletín, $\mathrm{N}^{\mathrm{o}}$ 01/13.063, JurisData: 2003-020386.

Senft con société Axa France, et autres (2007): Corte de Casación, $2^{a}$ sala en lo civil, publicada en Boletín, No 06-16.000, JurisData: 2007-037081.

Signerin con Société Aventis Pasteur MSD y otro, Corte de Casación, $1^{\mathrm{a}}$ sala en 258 lo civil, No $05-10.593$.

Siharath v. Sandoz Pharmaceuticals Corp. (2001): 131 F.Supp. 2d 1347. Disponible en http://law.justia.com/cases/federal/district-courts/FSupp2/ 131/1347/2579959/. [Fecha de consulta: 28 de agosto de 2014].

Sindell con Abbott Laboratories (1980): Corte Suprema de California. 20 de marzo de 1980. 26 C3d 588. Disponible en http://online.ceb.com/calcases/ C3/26C3d588.htm. [Fecha de consulta: 15 de agosto de 2014].

Smith con. CutterBiological, Inc., A Division of Miles Inc., 72 Haw. 416 (1991), citado por Benjamin Th. Greer (2007). "Market share liability shouldn't die: proposed application to agricultural pesticides and the need to refine the apportionment of liability". San Joaquin Agricultural Law Revierw. Vol. 17. Disponible en www.sjcl.edu/campus/images/stories/sjalr/volumes/V17N1C02. pdf. [Fecha de consulta: 18 de agosto de 2014].

Snell con Farrell(1990): 2 S.C.R. 311, 328. Disponible en http://scc-csc.lexum.com/ scc-csc/scc-csc/en/item/634/index.do. [Fecha de consulta: 25 de agosto de 2014].

Société la médicale de France con syndicat des copropriétaires avenue de saxe à paris $15^{\mathrm{e}}$ (2005): Corte de Casación, $2^{\mathrm{a}}$ sala en lo civil, publicada en Boletín, No 03-20.011, JurisData: 2005-028663.

Societé Pharma con X (2006): Corte de Casación, $1^{\text {a }}$ sala en lo civil, 7 de marzo de 2006, publicada en Boletín, No 04-16.179, JurisData: 2006-032552.

Societé Pharma con X (2006): Corte de Casación, $1^{\text {a }}$ sala en lo civil, 7 de marzo de 2006, publicada en Boletín, No 04-16.180, JurisData: 2006-032553. 
St-Jean v. Mercier(CA), (1999): Corte Suprema de Canadá. R.J.Q. 1658. Disponible en http://scc-csc.lexum.com/scc-csc/scc-csc/en/item/1953/index.do. [Fecha de consulta: 25 de agosto de 2014].

Suard con société UCB Pharma y otros (2009): Corte de Casación, 1ra sala en lo civil, 24 de septiembre de 2009, publicada en Boletín, N $^{0}$ 08-16.305, JurisData: 2009-049537.

Summers con Tice (1948): Corte Suprema de California. 17 de noviembre de 1948. 33 Ca1.2d 80, 199 P.2d 1. Disponible en http://law.justia.com/cases/ california/cal2d/33/80.html. [Fecha de consulta: 15 de agosto de 2014].

Wade-Greaux con WhitehallLaboratories (1994): 874 F. Supp. 1441 (D.V.I., 1994) Disponible en www.leagle.com/decision/19942315874FSupp1441_12101.xml/ WADE-GREAUX $\% 20 \mathrm{v} . \% 20$ WHITEHALL $\% 20$ LABORATORIES, $\% 20$ INC. [Fecha de consulta: 28 de agosto de 2014]. 